\title{
On the Remapping and Identification of Potential Wind Sites in Nigeria
}

\author{
Zaccheus 0. Olaofe \\ Climate System and Analysis Group, University of Cape Town, Rondebosch, South Africa \\ Email: zakky201@gmail.com
}

Received 13 August 2015; accepted 25 September 2015; published 28 September 2015

Copyright (C) 2015 by author and Scientific Research Publishing Inc.

This work is licensed under the Creative Commons Attribution International License (CC BY).

http://creativecommons.org/licenses/by/4.0/

(c) (i) Open Access

\section{Abstract}

The ERA-Interim reanalysis wind based on the distance-weighted average remapping for studying the wind circulation in Nigeria is presented. The wind flow using this atmospheric model simulation is studied for identification of grid-tie electrification opportunities in different wind locations. A 10-year reanalysis wind speed components at a surface level of the planetary layer at $0.25^{\circ} \times$ $0.25^{\circ}$ spatial resolution is obtained and remapped into a new horizontal wind field at a grid resolution of $0.125^{\circ} \times 0.125^{\circ}$ covering longitudinal and latitudinal directions of $3.0-15.0^{\circ} \mathrm{E}$ and 15.0 $3.0^{\circ} \mathrm{N}$, respectively. Using the distance-weighted average technique, the remapped wind field at a new grid resolution of $0.125^{\circ} \times 0.125^{\circ}$ is compared at different terrain elevations and approximated close to the actual wind field of the same resolution. To determine the suitability of the prevailing wind for small-scale energy conversion, the magnitude of wind flow across the remapped wind field is studied for a 10-year period. Analysis shows that northern regions of Nigeria have a fair wind potential for a stand-alone application based on the wind flow originated at Gulf of Guinea as well as Chad and Niger. Furthermore, hourly surface wind speed observations from 18 synoptic stations in Nigeria are obtained and compared with the bilinear interpolated wind stations. The reanalysis wind reflects the surface wind observations and proves that the prevailing wind in Nigeria is higher than the reanalysis wind projection obtained from gridded data at resolution of $0.125^{\circ} \times \mathbf{0 . 1 2 5}^{\circ}$. The sectorwise wind directions at each synoptic stations for a period of 10 years are presented.

\section{Keywords}

ERA-Interim Wind Components, Grid Resolutions, Relative Error, Distance-Weighted Remapping, Bilinear Interpolation, Nigeria

\section{Introduction}

Wind is produced when different forces of the atmosphere (such as the pressure gradient force, Coriolis force, 
frictional force and centripetal force) act on a parcel of air in motion from a high pressure to a low pressure region. In addition, the wind is primarily driven by differences in air pressure at two regions or levels, though rotation of the earth does have an influence on the direction of wind flow. The wind flows from a higher pressure to a lower pressure system in an attempt to balance the pressure at two different regions. These variations in air pressure are attributed to temperature differences caused by variations in solar energy received on earth surface. (That is, there is uneven heating of the earth surface by solar radiation which causes temperature differences and hence, atmospheric pressure differences across the surface which produces the wind). The balance of these forces in the vertical and horizontal directions gives rise to the different kinds of winds (gradient wind, thermal wind, geostrophic wind etc.). The frictional force is another atmospheric pressure that opposes the wind flow and causes the air parcel to turn slightly toward lower pressure region. Furthermore, the Coriolis force deflects the direction of wind flow to the right in Northern Hemisphere and to the left in Southern Hemisphere due to earth rotation. Hence, the pressure gradient force (pgf), frictional force, Coriolis force and centripetal force are the main drivers in wind circulation at any considered location. The interaction of these forces and the effects on wind flow are best understood using an atmospheric simulation.

An air parcel which is at initial rest will move from a high pressure to low pressure region due to the pressure gradient force. When the air parcel moves, it is deflected by the Coriolis. As the air parcel gains momentum, this wind deflection increases until the Coriolis force equals the pressure gradient force. This condition is called the geostrophic balance and at this point the air parcels are parallel to the isobars. Therefore, this movement of air parcels parallel to the isobars due to this balance is referred to as geostrophic winds. According to Nilsson and Ivanell [1], the geostrophic wind is found at altitude higher than $1 \mathrm{~km}$, largely driven by air temperature differences, and unaffected by the earth surface.

Several wind studies have been conducted on the analysis of wind speed distributions and power densities using the historical records at a reference or group of synoptic stations at different wind locations in Nigeria. However, no study has been conducted on the regional wind circulation in Nigeria, using a high resolution wind simulation from the climate mode. In the earlier wind study conducted by Aidan et al. [2], the surface wind obtained at 8 synoptic stations in the northern Nigeria where fitted using the Normal, Weibull, Rayleigh and Gamma probability density functions. They concluded their wind study at $80 \mathrm{~m}$ hub height to be very satisfactory for utility-scale power generation at four stations: Gusua, Kaduna, Maiduguri and Zaria. As presented by Fadare (2008), the author conducted a statistical wind energy analysis using daily wind records from station mast for 10 years period (1995-2004), obtained from the International Institute of Tropical Agriculture (IITA), Ibadan, Nigeria. The daily, monthly, seasonal, and yearly wind speeds were modeled using Weibull probaility density function. The annual mean wind speed in Ibadan was estimated at $2.75 \mathrm{~m} / \mathrm{s}$, while Weibull mean wind speed and the power density were estimated at $2.947 \mathrm{~m} / \mathrm{s}$ and $15.484 \mathrm{~W} \cdot \mathrm{m}^{-2}$, respectively. The author classified Ibadan city to be a low wind energy region. Ohunakin [3] in the study conducted a wind energy assessment using a 21 years station observations at Uyo city in Niger-Delta obtained from the Nigerian Meterological Agency (NIMET). The historical speed records (1986-2007) were statistically analyzed using both Weibull and Rayleigh density functions, and results show Uyo station to have mean wind speed of $3.17 \mathrm{~m} / \mathrm{s}$ and maximum at $3.67 \mathrm{~m} / \mathrm{s}$ with a corresponding wind power density approximated at $19.91 \mathrm{~W} \cdot \mathrm{m}^{-2}$ for a year's record. The mean wind speed at this station was not economically viable for a medium nor utility-scale energy application but suitable for small-scale application only as the station falls within class 1 of the international system of wind classification. Furthermore, a number of few wind studies have been conducted on assessments of the wind speed characteristics at different locations in Nigeria by Ojosu et al. [4] [5], Adekoya et al. [6], Anyanwu et al. [7], Agbaka [8], Igbokwe et al. [9], Medugu et al. [10], Ngala et al. [11] and Oriaku et al. [12]. In literature, the wind speed record was modeled using different analytical tools such as: statistical modeling (Weibull and Rayleigh distribution functions); Seasonal Autoregressive Integrated Moving Average Modeling; Linear and Multiple Regression modeling; stochastic simulation; and Artificial Neural Network (ANN).

A recent study on the development of medium-scale wind farm in Katsina-Nigeria was presented by Garba et $a l$. [13]. From the review on the wind studies conducted by different authors in Nigeria; using either the reference, a combination of different meterological observations or monthly mean wind records is not sufficient because most cities and synoptic stations have poor historical wind records and are unsuitable for regional resource assessment in Nigeria. Some of the synoptic observations had missing wind climatologies for different time of days, weeks and month making wind assessment difficult to carry out. This may be attributed to local topographic effects on the wind flow, power supply failure to the data logging systems deployed on meterological 
masts, missing observation due to data transmission error from the synoptic station to data centre, data logger failure, calibration error or degradation of existing sensors deployed on the various station masts. The effects of boom and other mounting arrangement around a synoptic mast may introduce a large bias in wind sensing as shown in the wind tunnel studies conducted by Pedersen et al. [14]. Due to the effect of local topography on the wind flow at different geographical locations in Nigeria, a low quality of historical wind records due to deterioration of weather sensors (such as temperature, pressure, turbulence or cup anemometer mechanisms) as well as insufficient synoptic stations at strategic locations for wind measurements on regional scale in Nigeria, a mesoscale wind modeling covering the landmark is required. The mesoscale modeling has an acceptable accuracy level, very cost-effective and provides long-term wind resource estimates over geographical locations with limited in situ measurements or at synoptic stations with no historical wind climates. Using low quality wind observations often leads to a poor guide in the identification and mapping of potential locations for wind atlas development [15]. Furthermore, the solid state wind sensors deployed on synoptic masts have replaced the traditional mechanical cup anemometers because of the following: interference of the station tower, boom and other mounting arrangements obstructing the wind flow, the anemometer design and calibration procedure, response to turbulence characteristics of the wind flow, atmospheric stability measurement needs, deterioration of mechanical parts of the cup anemometer at stations due to harsh weather conditions [16].

The ERA-Interim simulation is a global atmospheric reanalysis dataset produced by the European Centre for Medium-Range Weather Forecasts (ECMWF). The ERA reanalysis dataset provides a multivariate, spatially complete, and coherent records of the global atmospheric circulation. The atmospheric model, data assimilation method, and the in situ observations used in producing the ERA-Interim dataset as well as the basic performance evaluation are discussed by Dee et al. [17].

Though, ERA-Interimwind datasets have insufficient resolution to allow for direct utilization in wind resource assessment (lower resolution of the model output and the coarse representation of orography over the land-sea surface), however, they can be used to: provide the boundary conditions to mesoscale modeling capable of deriving wind climatologies at a higher resolution on regional scale; resolve local and regional circulation patterns and the atmospheric boundary layer, and can be applied over domains of several hundreds of kilometers squared covered with a grid mesh with a resolutions of a few kilometers [18] [19]. In summary, the ERA-Interim wind reanalysis dataset provides a global view that encompasses many essential climate variables in a physically consistent framework with only a short time delay. For wind assessment study, it can be used to provide a global view on the wind circulation at desired geographical location. The application of the reanalysis wind has been presented by Buzzi et al. [20] where the ECMWF reanalysis data was used to provide boundary conditions for the parallel version of the hydrostatic model BOLAM (Bologna Limited Area Model) for generating the wind statistics over the Mediterranean over a 2 years period at a $10 \mathrm{~km}$ grid resolution.

In this study, the ERA-Interim wind speed components are utilized for studying the wind flow into Nigeria, originated at Gulf of Guinea and two neighbouring countries (Chad and Niger). The wind circulation is studied for identification and mapping of wind potential sites in Nigeria. The wind flow from Gulf of Guinea originated from Guinea and Benguela currents, while Chad and Niger flow originated from Mediterranean Sea. The considered geographical coordinates of the proposed wind field covers longitudinal and latitudinal directions of 3.0 - $15.0^{\circ} \mathrm{E}$ and $15.0-3.0^{\circ} \mathrm{N}$, respectively as shown in Figure 1(a), Figure 1(b). The 10 meter $\mathrm{U}$ and $\mathrm{V}$ wind components from the ERA-Interim dataset at a temporal resolution of 00:00:00, 06:00:00, 12:00:00 and 18:00:00 UTC for period of 2005-2014 are obtained on spatial resolutions of $0.125^{\circ} \times 0.125^{\circ}$ and $0.25^{\circ} \times 0.25^{\circ}$ [21]. Using the wind speed components at a grid resolution of $0.25^{\circ} \times 0.25^{\circ}$ (dimension $=2401$, number of grid points in the longitudinal direction " $n_{x}$ " $=49$, number of grid points in the longitudinal direction " $n_{y}$ " $=49$ ), within a geographical coordinates boundary of $\lambda_{x}=3-15^{\circ} \mathrm{E}, \varphi_{y}=15-3^{\circ} \mathrm{N}$, a new wind field is desired at a higher resolution of $0.125^{\circ} \times 0.125^{\circ}$ (dimension $=9469, n_{x}=97, n_{y}=97$ ) for the coordinates of $\lambda_{x}=3-15^{\circ} \mathrm{E}, \varphi_{y}=15-3^{\circ} \mathrm{N}$. A grid description of the source wind dataset on $0.25^{\circ} \times 0.25^{\circ}$ resolution is used to reproduce a wind field on a new grid resolution of $0.125^{\circ} \times 0.125^{\circ}$ using the concept of distance-weighted average remapping. To prepare a platform for evaluation of the remapped wind field and determining the accuracy of distance-weighted average technique in remapping from one grid resolution to another, the distance-weighted wind speed components at a new grid resolution of $0.125^{\circ} \times 0.125^{\circ}$ (dimension $=9469, n_{x}=97, n_{y}=97$ ) are compared against the actual wind speed components at the same grid resolution (dimension $=9469, n_{x}=97, n_{y}=97$ ) using the following tools: 1 ) the climate data operator and 2) ferret running on a linux-based machine. The estimated daily, monthly and annual wind speed biases show that the gridded wind components on a grid field of $0.25^{\circ} \times 0.25^{\circ}$ resolution can be 


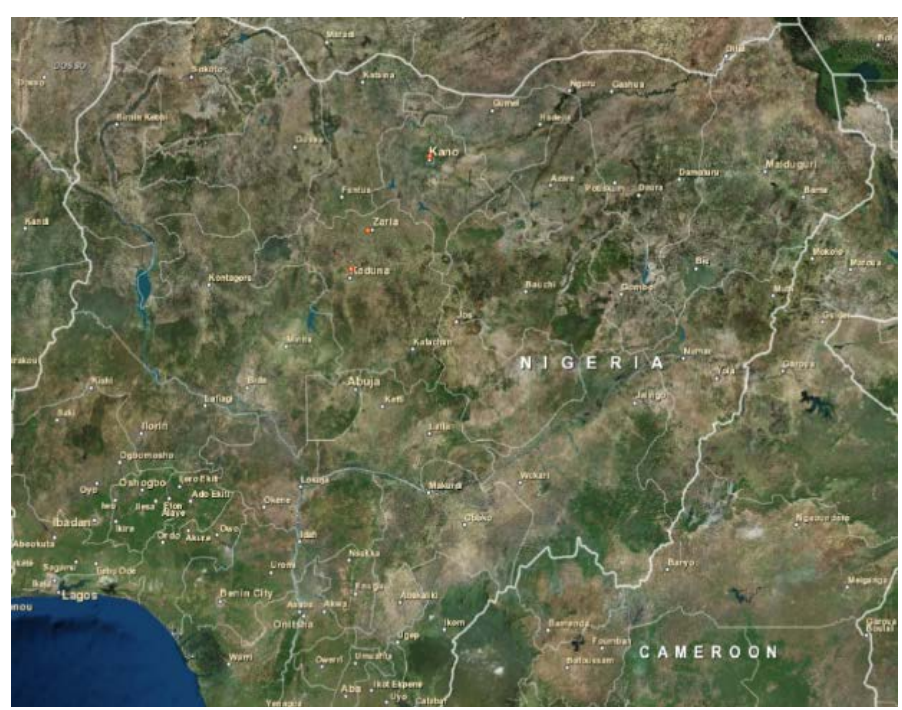

(a)

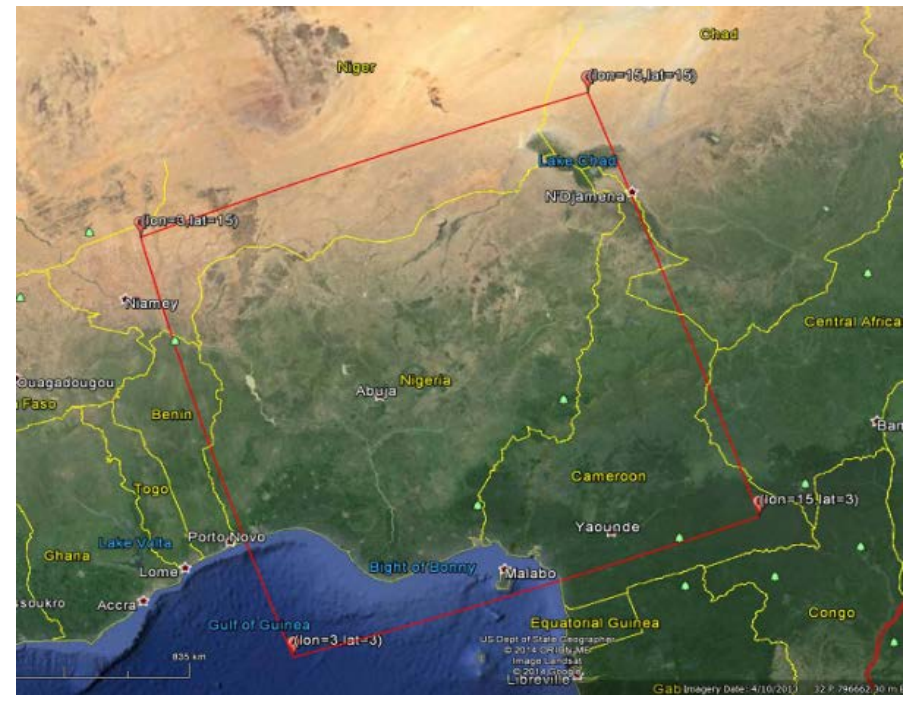

(b)

Figure 1. (a) Capturing of different locations on Nigeria map for wind flow study; (b) Geographical coordinates mapping of Nigeria land mark.

remapped into a higher resolution for smooth and flat terrain, and may be substituted with gridded dataset on a wind field of $0.125^{\circ} \times 0.125^{\circ}$ grid resolution. For complex terrain at different locations in Nigeria, the remapped wind field deviates from the actual wind field of the same resolution. Furthermore, the wind speed chart for 10 years period using the remapped and actual wind fields at $0.125^{\circ} \times 0.125^{\circ}$ resolution is produced. To identify wind potential region, the bilinear interpolation on the remapped wind field $\left(0.125^{\circ} \times 0.125^{\circ}\right.$, dimension $=9469$, $\left.n_{x}=97, n_{y}=97\right)$ was done to obtain the wind speed gridded datasets for 18 synoptic stations within the considered geographical coordinates of the wind field.

According to the World Meteorological Organization (WMO) list containing surface and upper-air weather stations' records for synoptic applications, the Nigerian Meteorological Agency (NIMET) has a number of synoptic stations at coordinates of $\lambda_{x}=3-15^{\circ} \mathrm{E}, \varphi_{y}=15-3^{\circ} \mathrm{N}$. Using the geographical coordinates of the considered 18 synoptic stations, the hourly surface wind observations available for these stations in Nigeria are obtained from the National Ocean and Atmospheric Administration (NOAA) database [22]. The hourly surface wind observation for each weather station is available and converted to monthly and annual mean wind observations. 
The ERA monthly and annual wind speed for each station are estimated, and compared with the monthly and annual surface wind observation available for each synoptic station. The remapped wind field approximated close to the actual wind field at a smooth and flat terrain while the discrepancies of the remapped wind field from the actual wind field increased with terrain elevations and contours. Comparisons of the wind statistics for 18 synoptic stations using the ERA wind simulation and surface wind are presented. The reanalysis wind reflects the wind flow for identification of potential wind locations in Nigeria. Based on the direction of wind flow from Gulf of Guinea as well as Chad and Niger into Nigeria, the wind sites in northern Nigeria suitable for grid-tie electrification are identified. Section three discussed the methodologies for remapping of gridded dataset and validation of remapped wind field; the wind flow convergence and divergence as well as the wind resource distribution over a $10 \mathrm{~m}$ AGL at different geographical locations in Nigeria for identification of wind potential sites in Nigeria is discussed in section four. Conclusion is made on the prospective of wind energy investment in Nigeria.

\section{Data Collection}

The first step in wind flow study for identification of wind potential wind sites in Nigeria is to identify and map the area of interest. To capture the map of Nigeria as shown in Figure 1(a), a landmark covering longitudinal and latitudinal directions of $3.0-15.0^{\circ} \mathrm{E}$ and $15.0-3.0^{\circ} \mathrm{N}$ is considered. In an attempt to capture the entire landmark of Nigeria, a portion of few cities at Cameroon, Chad and Niger were captured alongside as shown in Figure 1(b). In addition, the considered geographical coordinates are clipped on google earth as $x_{1}=\left(\operatorname{lon}_{1}=3.0^{\circ}\right.$, lat $\left._{1}=3.0^{\circ}\right), x_{2}=\left(\operatorname{lon}_{1}=3.0^{\circ}, \operatorname{lat}_{2}=15.0^{\circ}\right), x_{3}=\left(\operatorname{lon}_{2}=15.0^{\circ}\right.$, lat $\left.2=15.0^{\circ}\right)$, and $x_{4}=\left(\operatorname{lon}_{2}=15.0^{\circ}\right.$, lat $\left._{1}=3.0^{\circ}\right)$, respectively. The desired wind speed components in the ERA-Interim reanalysis datasets at these geographical coordinates are extracted. The wind speed components (10 meter $\mathrm{U}$ and $\mathrm{V}$ wind speed components) at temporal resolutions of 00:00:00, 06:00:00, 12:00:00, and 18:00:00 UTC for a period of 2005-2014 were obtained from the European Centre for Medium-Range Weather Forecasts (ECMWF) database [21]. From the wind statistics of the ERA wind speed components, a total of 14, 608 data points for 10 years period was available for this wind flow study. The considered wind speed components on the surface level are on a regular grid resolutions of $0.125^{\circ} \times 0.125^{\circ}\left(\right.$ dimension $\left.=9409, n_{x}=97, n_{y}=97\right)$ and $0.25^{\circ} \times 0.25^{\circ}\left(\right.$ dimension $\left.=2401, n_{x}=49, n_{y}=49\right)$. The wind statistics of these grid resolutions are summarized in Figure 2(a), Figure 2(b), respectively.

In addition, historical wind climatology for global weather stations is freely available on National Ocean and Atmospheric Administration (NOAA) web. The web contains datasets from global automated weather observing systems (AWOS) which are operated and controlled by the Federal Aviation Administration. The AWOS data are archived in the global surface hourly database with record from as early as 1901 [22].

To prepare a platform for evaluation and comparison of the bilinear interpolated stations on the remapped wind field, the historical wind observations at 18 stations on $10 \mathrm{~m}$ height AGL were obtained online from NOAA. Quality check on the hourly surface wind observations was made for each synoptic station and Table 1 summarizes the annual surface wind observations available for each station on a $10 \mathrm{~m}$ height above ground level (AGL).

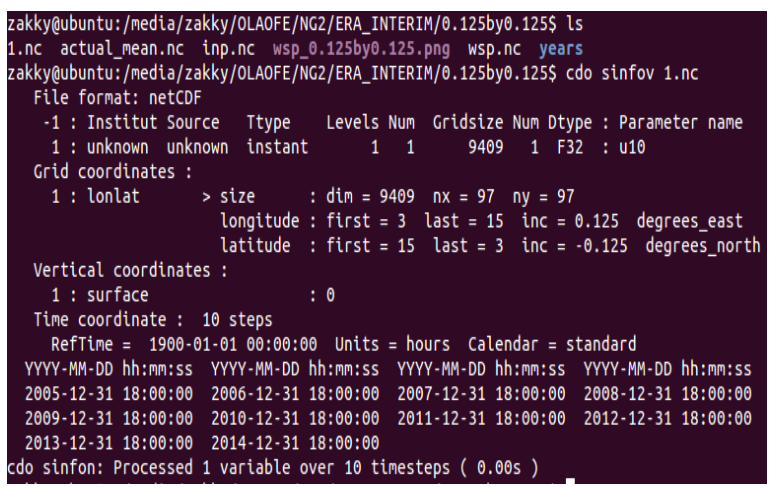

(a)

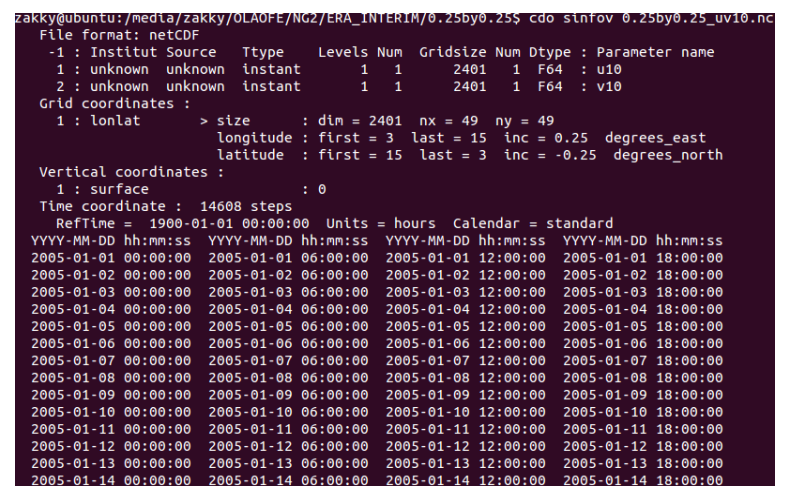

(b)

Figure 2. (a) Wind field information on $0.125^{\circ} \times 0.125^{\circ}$ grid resolution; (b) Wind field information on $0.25^{\circ} \times 0.25^{\circ}$ grid resolution. 
Table 1. Summary of the total hourly surface wind observations available for 18 synoptic stations in Nigeria.

\begin{tabular}{|c|c|c|c|c|c|c|c|c|c|c|c|}
\hline State & 2005 & 2006 & 2007 & 2008 & 2009 & 2010 & 2011 & 2012 & 2013 & 2014 & Total \\
\hline Ngu. & - & 14 & 2 & 35 & 121 & 52 & 6 & 1 & 2 & 1 & 234 \\
\hline Kat. & 5 & 92 & - & 120 & 206 & 292 & 822 & 276 & 450 & 1396 & 3654 \\
\hline Maid. & 203 & 130 & 1 & 16 & 477 & 603 & 31 & 3 & 170 & - & 1634 \\
\hline Soko. & 367 & 488 & 37 & 161 & 1823 & 1515 & 480 & 38 & 266 & 975 & 5783 \\
\hline Zar. & 1 & 62 & 161 & 442 & 135 & 719 & 509 & 124 & 132 & 406 & 2690 \\
\hline Gus. & - & 1 & - & - & - & - & - & - & - & - & 1 \\
\hline Pot. & - & 83 & 4 & 78 & 44 & 101 & 148 & 128 & 22 & 79 & 687 \\
\hline Kan. & 746 & 1266 & 295 & 1681 & 4330 & 2377 & 2689 & 1368 & 1980 & 3056 & 19,042 \\
\hline Keb. & 294 & 670 & 361 & 2011 & 3518 & 3144 & 1870 & - & - & 1 & 11,575 \\
\hline Gom & - & - & - & - & - & - & - & 21 & 182 & 571 & 774 \\
\hline Kad. & 786 & 919 & 112 & 1138 & 2472 & 2641 & 3314 & 1069 & 923 & 396 & 12,984 \\
\hline Yelwa & 1 & - & - & 453 & 170 & 333 & 816 & 846 & 669 & 290 & 3578 \\
\hline Bau & 220 & 238 & 19 & 134 & 323 & 408 & 278 & 72 & 15 & - & 1707 \\
\hline Makur. & 105 & 38 & 45 & 285 & 280 & 604 & 726 & 527 & 621 & 450 & 3576 \\
\hline Lok & 58 & - & 9 & 288 & 286 & 418 & 384 & 924 & 458 & 133 & 2900 \\
\hline Bida & - & - & 36 & 1036 & 1369 & 1823 & 1462 & 1530 & 1032 & 407 & 8695 \\
\hline Benin & - & 433 & 298 & 295 & 446 & 956 & 748 & 225 & 380 & 581 & 4362 \\
\hline Calab & 225 & 144 & 7 & 96 & 1310 & 1396 & 1283 & 732 & 593 & 1009 & 6795 \\
\hline
\end{tabular}

\section{Methodology}

Two climate data tools running on the linux-based machine (workstation): climate data operator for manipulating and analysing climate model output and ferret for graphical display of the wind flow, were utilized for this study as shown in Figures 4-22. Upon the completion of data collection phase for the proposed wind flow study, the next procedure is to determine the grid information or metadata of the source wind speed components $\left(0.25^{\circ}\right.$ $\times 0.25^{\circ}$, dimension $=2401, n_{x}=49, n_{y}=49$ ) as presented in Figure $2(b)$. Thereafter, a new grid description file is written for remapping of the wind field into a new horizontal grid resolution $\left(0.125^{\circ} \times 0.125^{\circ}\right.$, dimension $=$ 9409, $n_{x}=97, n_{y}=97$ ) as summarized in Figure 3.

\subsection{Remapping of Wind Field}

The wind flow originated at Gulf of Guinea as well as two neighbouring countries "Chad and Niger" is studied using the source grid description file produced at a resolution of $0.25^{\circ} \times 0.25^{\circ}$ (dimension $=2401, n_{x}=49, n_{y}=$ 49).

Given a native resolution gridded data on global resolution of $0.125^{\circ} \times 0.125^{\circ}$, the desired horizontal grid associated with reanalysis wind speed components indexed at $n_{x}=1$ and $n_{y}=1$ represents a reference grid point located at longitudinal and latitudinal directions of $3.0^{\circ} \mathrm{E}$ and $15.0^{\circ} \mathrm{N}$, respectively. The longitudinal and latitudinal directions of the desired wind field as a function of their indices $\left(n_{x}, n_{y}\right)$ can be estimated from the expressions [23]:

$$
\lambda_{x}\left({ }^{\circ} \mathrm{E}\right)=3+(\Delta \lambda)_{n}\left(n_{x}-1\right) \text { where } n_{x}=1,2,3 \cdots 97
$$




$$
\varphi_{y}\left({ }^{\circ} \mathrm{N}\right)=15-(\Delta \varphi)_{n}\left(n_{y}-1\right) \text { where } n_{y}=1,2,3 \cdots 97
$$

where $n_{x}$ and $n_{y}$ are the number of grid points in the longitudinal and latitudinal directions, respectively; $(\Delta \lambda)_{n}$ is the grid resolution between two points in the longitudinal direction; $(\Delta \varphi)_{n}$ is the grid resolution between two points in the latitudinal direction.

Note: $3^{\circ} \mathrm{E}$ and $15^{\circ} \mathrm{N}$ are the reference grid point of the desire wind field and extends to $\lambda_{x}\left({ }^{\circ} \mathrm{E}\right)$ and $\varphi_{y}\left({ }^{\circ} \mathrm{N}\right)$ in the longitudinal and latitudinal directions, respectively.

Using Equations (1)-(2), the longitudinal and latitudinal directions of the desired wind field on a grid indexed $\left(n_{x}=97, n_{y}=97\right),(\Delta \lambda)_{n}=0.125^{\circ},(\Delta \varphi)_{n}=0.125^{\circ}$ at reference grid indexed $\left(n_{x}=1, n_{y}=1\right)$ gives $\lambda_{x}=\left(15^{\circ} \mathrm{E}\right), \varphi_{y}=$ $\left(3^{\circ} \mathrm{N}\right)$. Therefore, a desired wind field on the grid dimension of $9409\left(n_{x}=97, n_{y}=97\right),(\Delta \lambda)_{n}=0.125^{\circ},(\Delta \varphi)_{n}=$ $0.125^{\circ}$ corresponds to a new wind field on a longitudinal and latitudinal directions of $3.0-15.0^{\circ} \mathrm{E}$ and $15.0-$ $3.0^{\circ} \mathrm{N}$ as shown in Figure 3. Hence, a new grid description file is produced for remapping an old wind field on grid dimension of $2401\left(n_{x}=49, n_{y}=49\right),(\Delta \lambda)_{n}=0.25^{\circ},(\Delta \varphi)_{n}=0.25^{\circ}$ to a new wind field on dimension of 9409 $\left(n_{x}=97, n_{y}=97\right),(\Delta \lambda)_{n}=0.125^{\circ}$ and $(\Delta \varphi)_{n}=0.125^{\circ}$. The remapped wind field on a resolution of $0.125^{\circ} \times 0.125^{\circ}$ $\left(n_{x}=97, n_{y}=97\right)$ utilized for the wind flow study for 10 years period is presented in Figures 4(a)-13(a). For comparisons, the wind speed datasets for the actual field on a grid resolution of $0.125^{\circ} \times 0.125^{\circ}\left(n_{x}=97, n_{y}=97\right)$ was obtained as shown in Figures 4(b)-13(b). The annual mean wind flow of the remapped and actual wind fields on the same geographical coordinates of $\lambda_{x}=\left(3-15^{\circ} \mathrm{E}\right), \varphi_{y}=\left(15-3^{\circ} \mathrm{N}\right)$ are compared. Finally, a $10-\mathrm{year}$ mean wind speed (m/s) chart for the remapped and actual wind fields on a grid resolution of $0.125^{\circ} \times 0.125^{\circ}$ are shown in Figure 14(a), Figure 14(b).

Table 2 summarized the minimum $(\mathrm{m} / \mathrm{s})$, mean $(\mathrm{m} / \mathrm{s})$ and maximum $(\mathrm{m} / \mathrm{s})$ wind speeds for the remapped field presented in Figure 14(a), and ranges between 0.00 and $12.40 \mathrm{~m} / \mathrm{s}$. From the above mentioned figures, the remapped wind field approximated close to the actual field at smooth and flat terrain and the discrepancies from the actual wind field increased with terrain elevations and contours.

\subsection{Validation of Remapped with Actual Wind Fields}

In the section 3.1, the gridded datasets of the wind field on a resolution of $0.25^{\circ} \times 0.25^{\circ}$ was transformed to a new gridded wind field on a resolution of $0.125^{\circ} \times 0.125^{\circ}$. In determining if the distance-weighted remapping of the field underestimated or overestimated the wind originated at Gulf of Guinea as well as at Chad and Niger into Nigeria, the wind speed values of the remapped field is compared with the actual wind field of the same grid resolution, covering the same longitudinal and latitudinal directions of $\lambda_{x}=3-15^{\circ} \mathrm{E}, \varphi_{y}=15-3^{\circ} \mathrm{N}$.

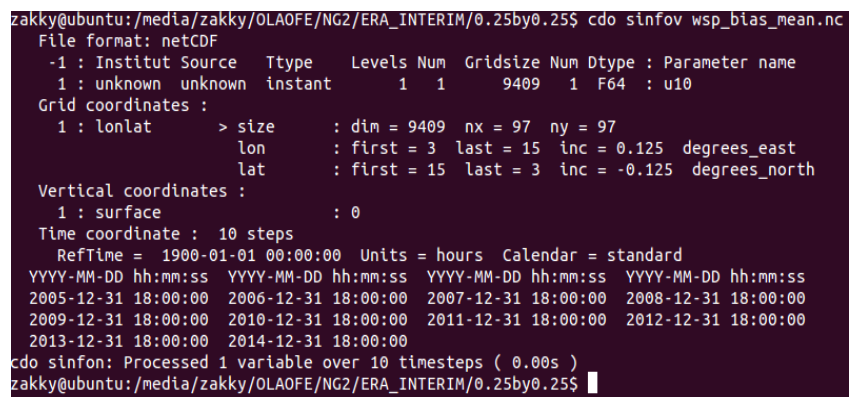

Figure 3. Remapped wind field information on $0.125^{\circ} \times 0.125^{\circ}$ grid resolution.

Table 2. Summary of the minimum $(\mathrm{m} / \mathrm{s})$, mean $(\mathrm{m} / \mathrm{s})$ and maximum $(\mathrm{m} / \mathrm{s})$ wind speeds of the remapped field.

\begin{tabular}{cccccccccccccc}
\hline WSP & 2005 & 2006 & 2007 & 2008 & 2009 & 2010 & 2011 & 2012 & 2013 & 2014 & Average \\
\hline Min & 0.001 & 0.001 & 0.001 & 0.001 & 0.002 & 0.000 & 0.001 & 0.001 & 0.001 & 0.001 & 0.001 \\
Mean & 2.69 & 2.66 & 2.76 & 2.67 & 2.59 & 2.64 & 2.71 & 2.62 & 2.57 & 2.60 & 2.65 & 1 & 1 \\
Max & 10.94 & 11.20 & 12.10 & 11.25 & 11.24 & 12.40 & 11.68 & 11.91 & 10.52 & 10.66 & 11.39 \\
\hline
\end{tabular}

Note: Min denotes minimum, Max denotes maximum and WSP denotes wind speed. 


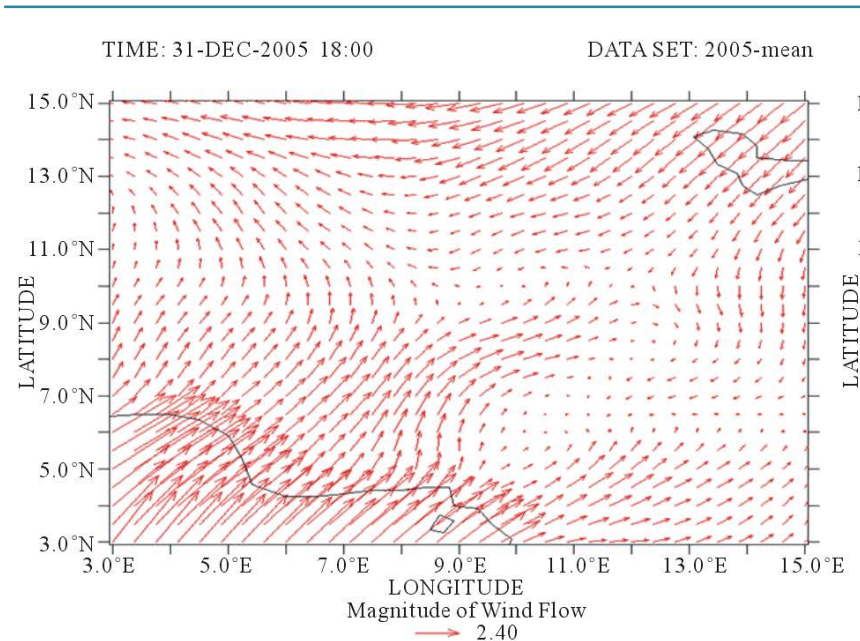

(a)
TIME: 31-DEC-2005 18:00

DATA SET: 2005-mean

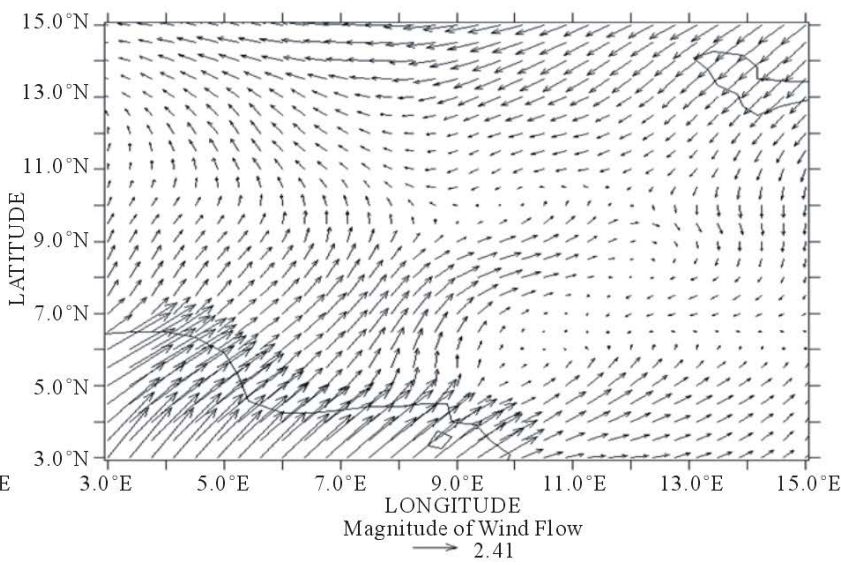

(b)

Figure 4. (a) Remapped wind field on $0.125^{\circ} \times 0.125^{\circ}$; (b) Actual wind field on $0.125^{\circ} \times 0.125^{\circ}$ grid resolution.

TIME: 31-DEC-2006 18:00

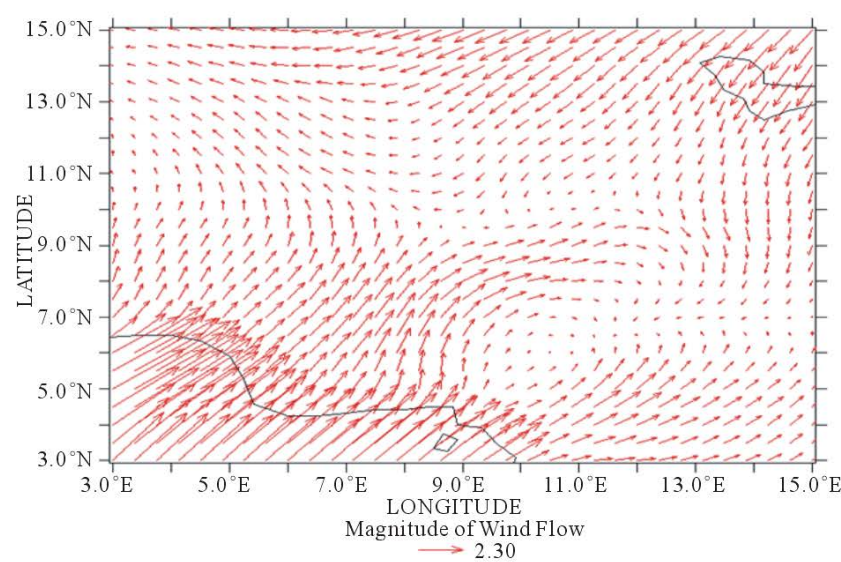

(a)
TIME: 31-DEC-2006 18:00

DATA SET: 2006-mean

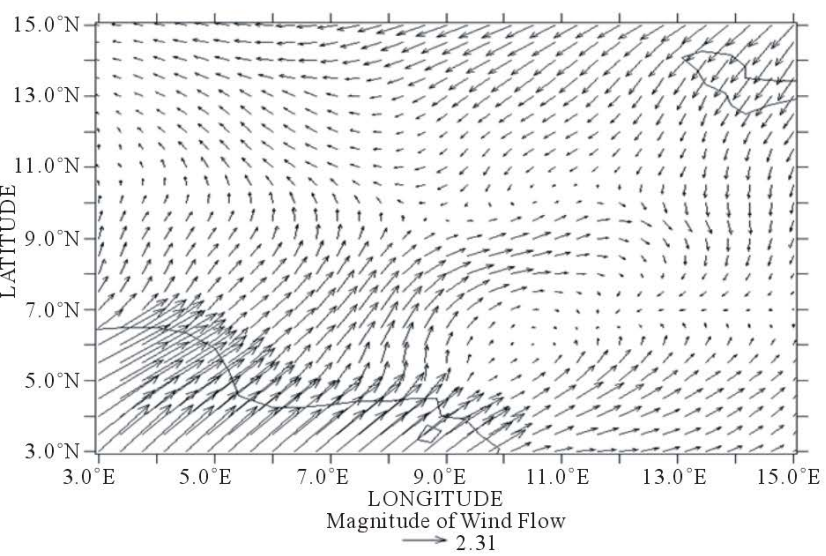

(b)

Figure 5. (a) Remapped wind field on $0.125^{\circ} \times 0.125^{\circ}$; (b) Actual wind field on $0.125^{\circ} \times 0.125^{\circ}$ grid resolution .

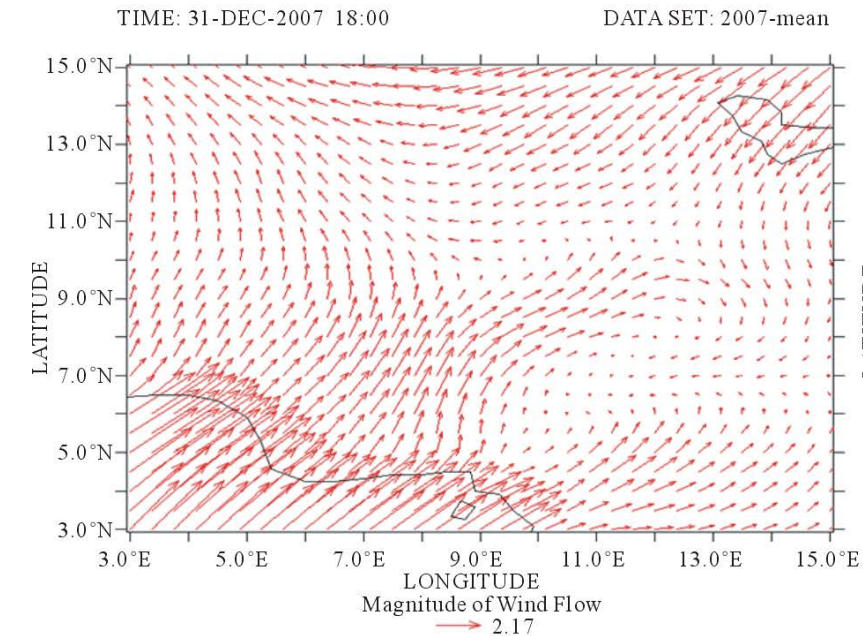

(a)
TIME: 31-DEC-2007 18:00

DATA SET: 2007-mean

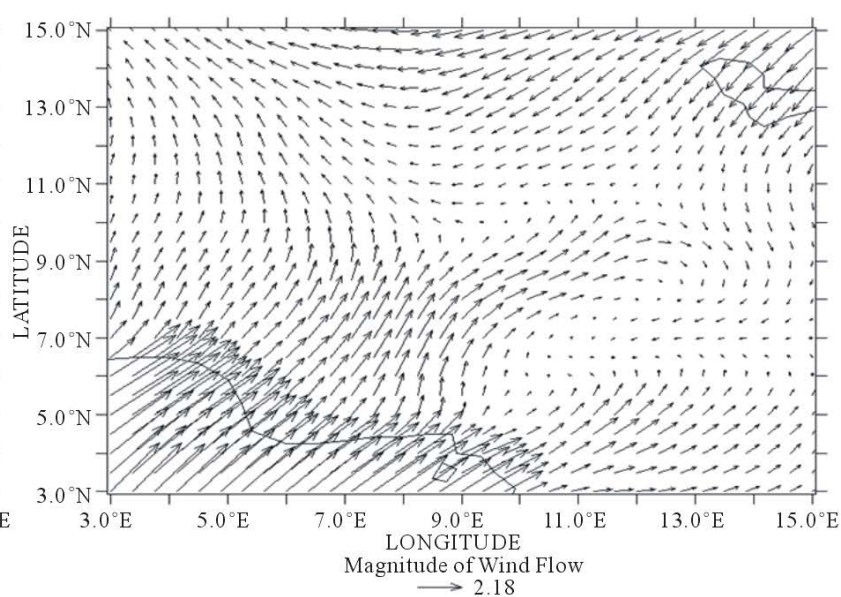

(b)

Figure 6. (a) Remapped wind field on $0.125^{\circ} \times 0.125^{\circ}$; (b) Actual wind field on $0.125^{\circ} \times 0.125^{\circ}$ grid resolution. 


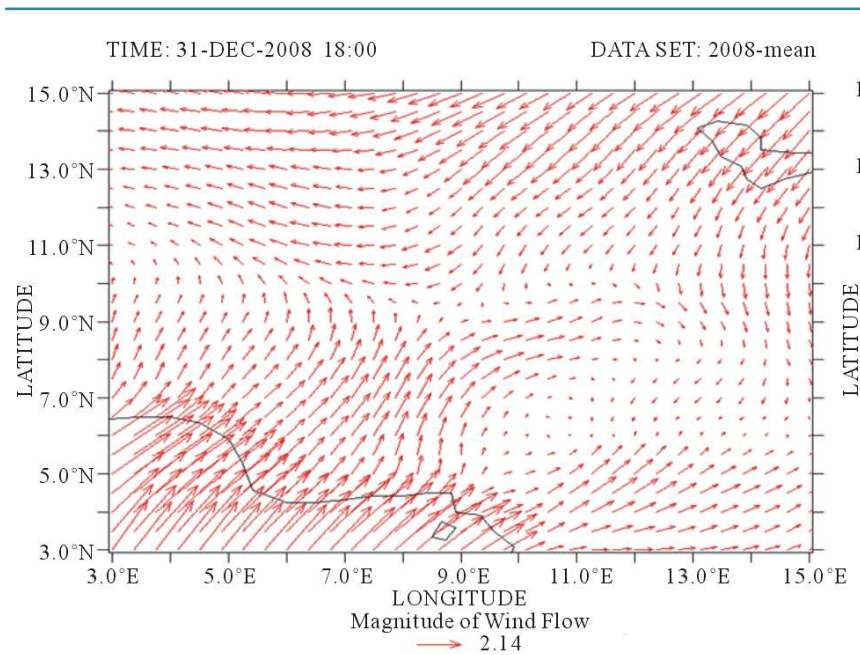

(a)

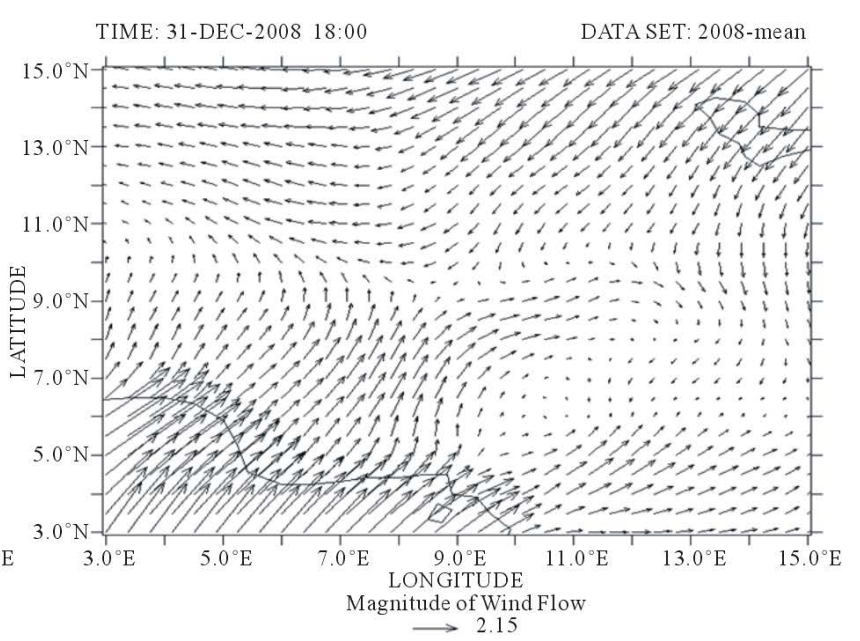

(b)

Figure 7. (a) Remapped wind field on $0.125^{\circ} \times 0.125^{\circ}$; (b) Actual wind field on $0.125^{\circ} \times 0.125^{\circ}$ grid resolution.

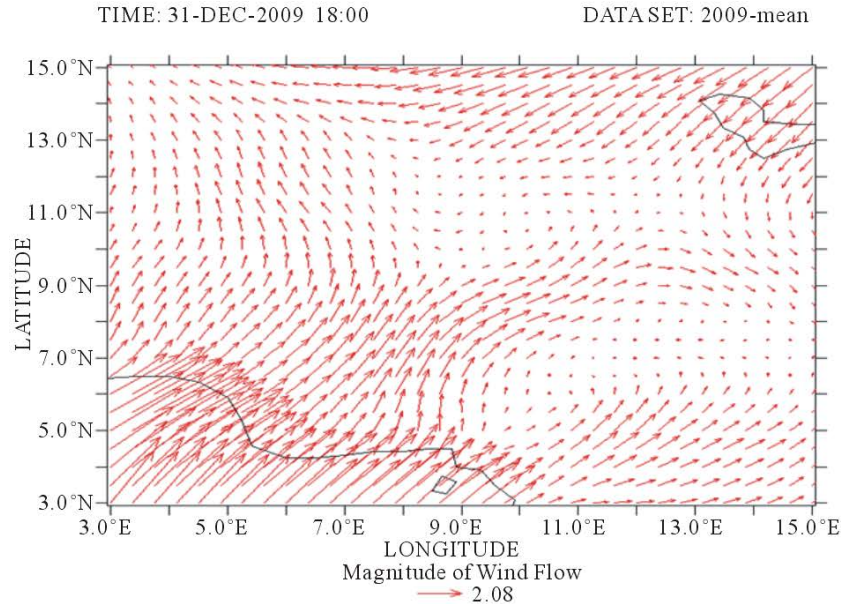

(a)
TIME: 31-DEC-2009 18:00

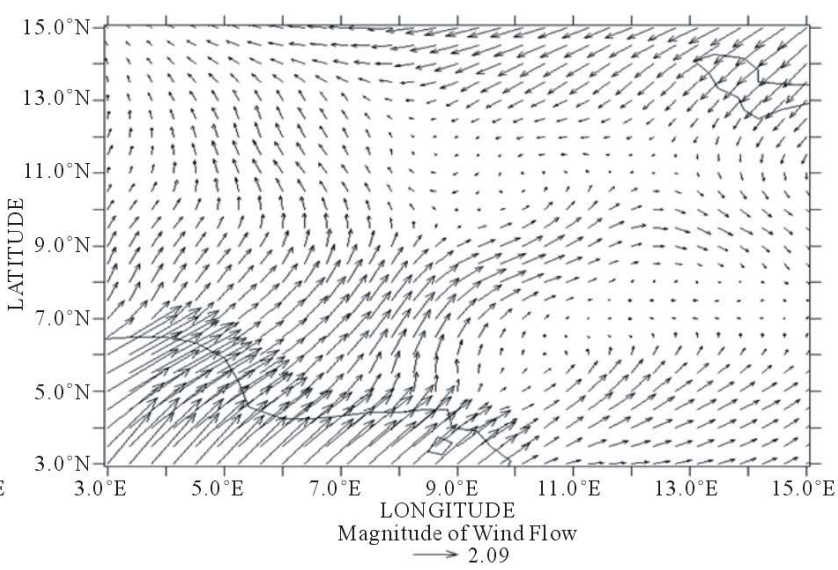

(b)

Figure 8. (a) Remapped wind field on $0.125^{\circ} \times 0.125^{\circ}$; (b) Actual wind field on $0.125^{\circ} \times 0.125^{\circ}$ grid resolution.

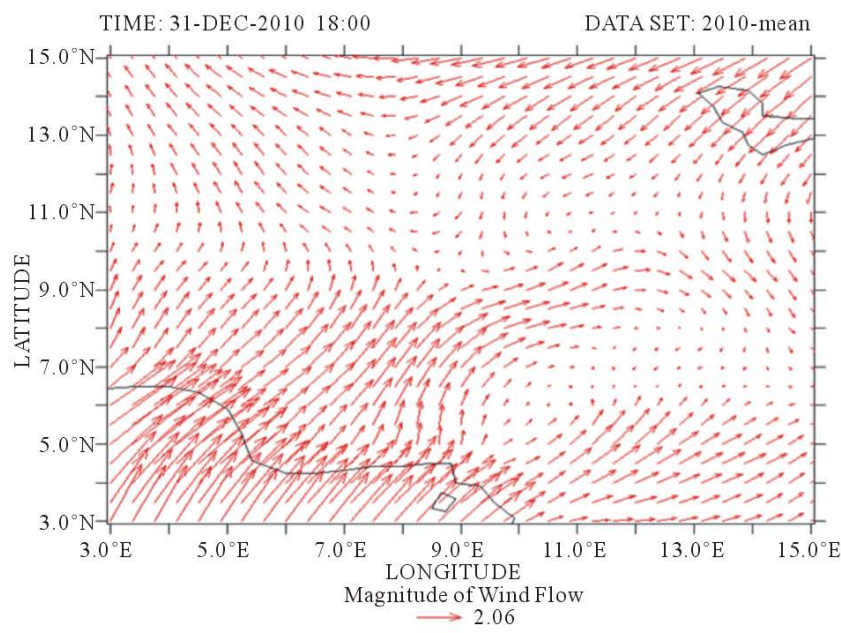

(a)

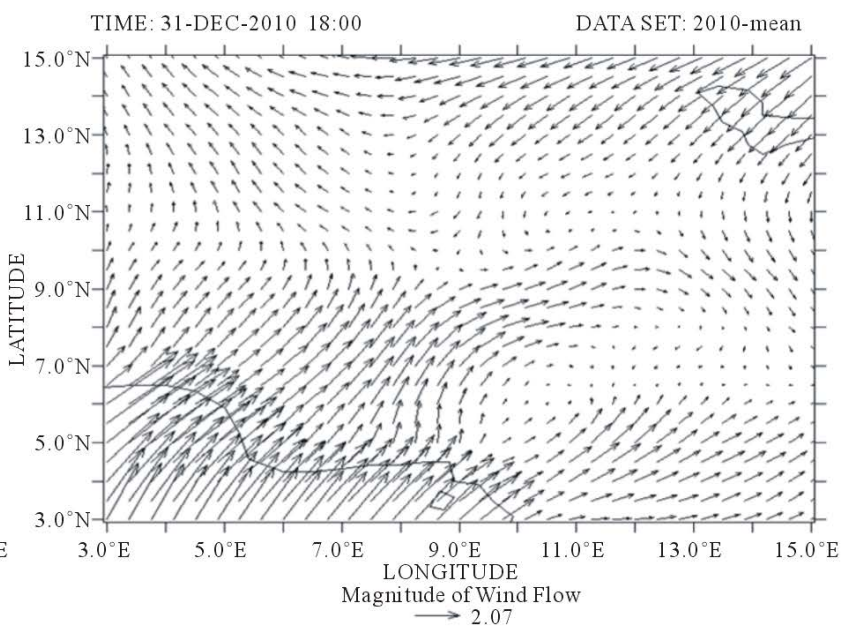

(b)

Figure 9. (a) Remapped wind field on $0.125^{\circ} \times 0.125^{\circ}$; (b) Actual wind field on $0.125^{\circ} \times 0.125^{\circ}$ grid resolution. 


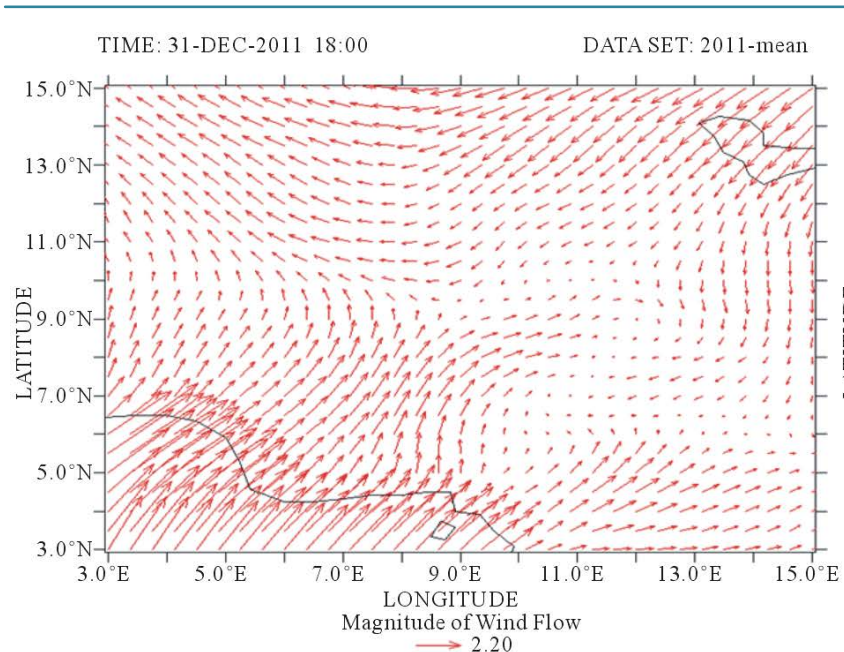

(a)

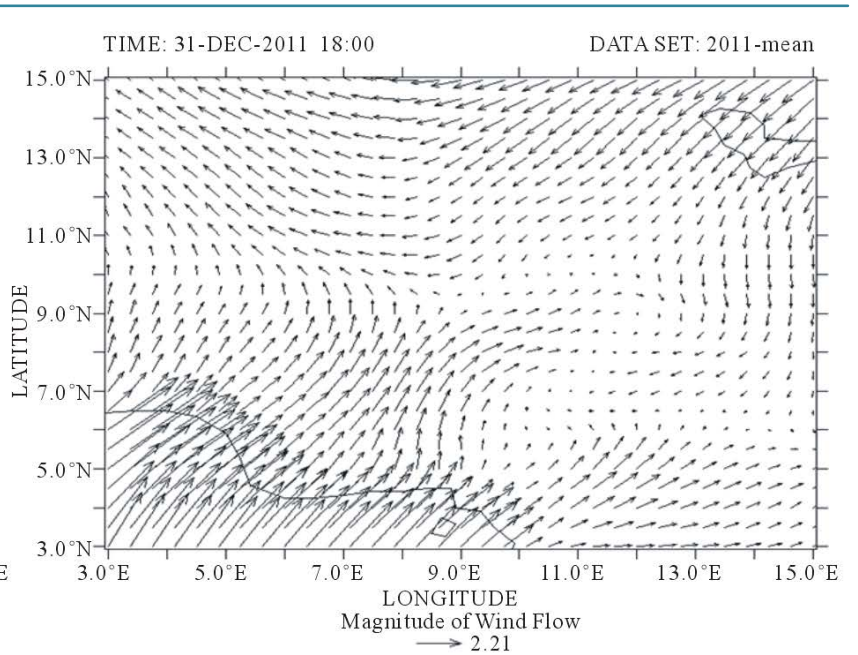

(b)

Figure 10. (a) Remapped wind field on $0.125^{\circ} \times 0.125^{\circ}$; (b) Actual wind field on $0.125^{\circ} \times 0.125^{\circ}$ grid resolution.

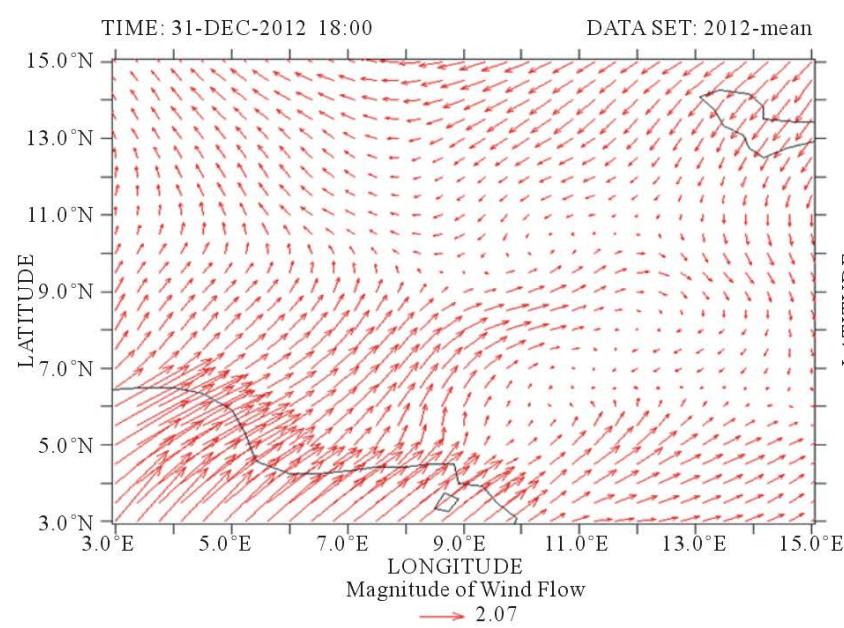

(a)

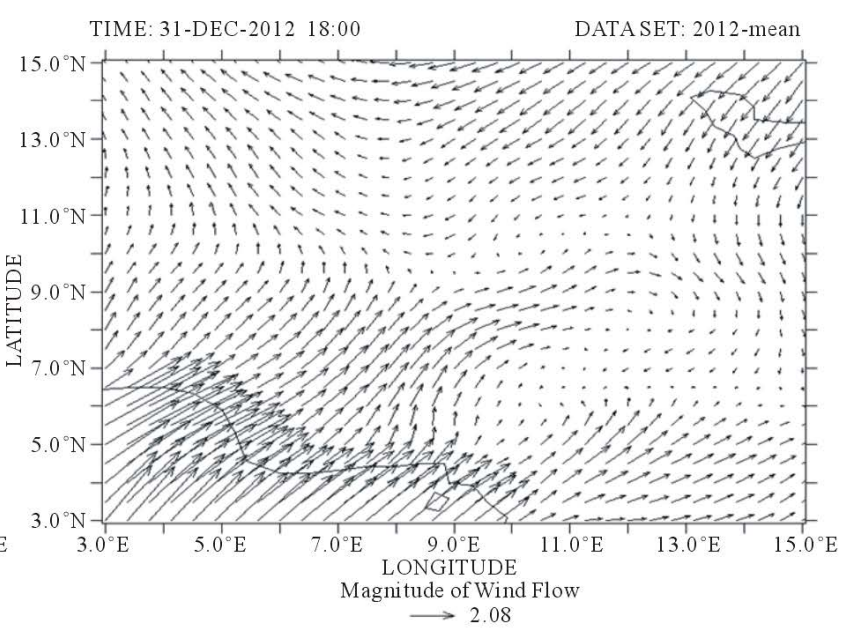

(b)

Figure 11. (a) Remapped wind field on $0.125^{\circ} \times 0.125^{\circ}$; (b) Actual wind field on $0.125^{\circ} \times 0.125^{\circ}$ grid resolution.

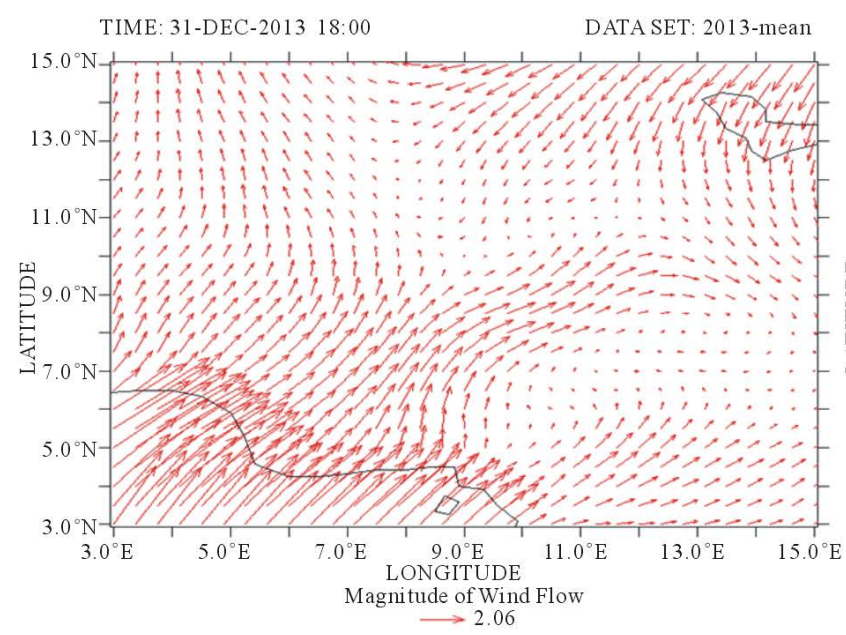

(a)

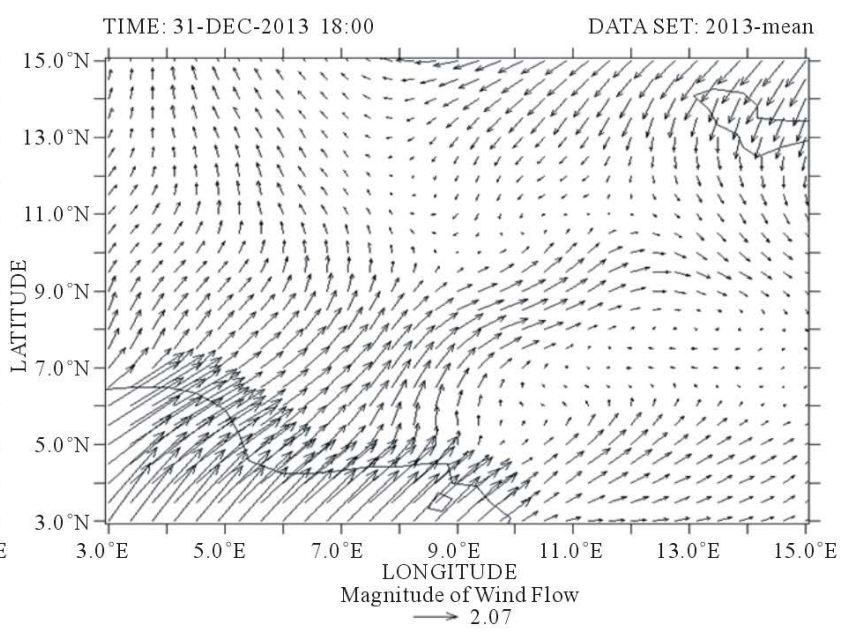

(b)

Figure 12. (a) Remapped wind field on $0.125^{\circ} \times 0.125^{\circ}$; (b) Actual wind field on $0.125^{\circ} \times 0.125^{\circ}$ grid resolution. 


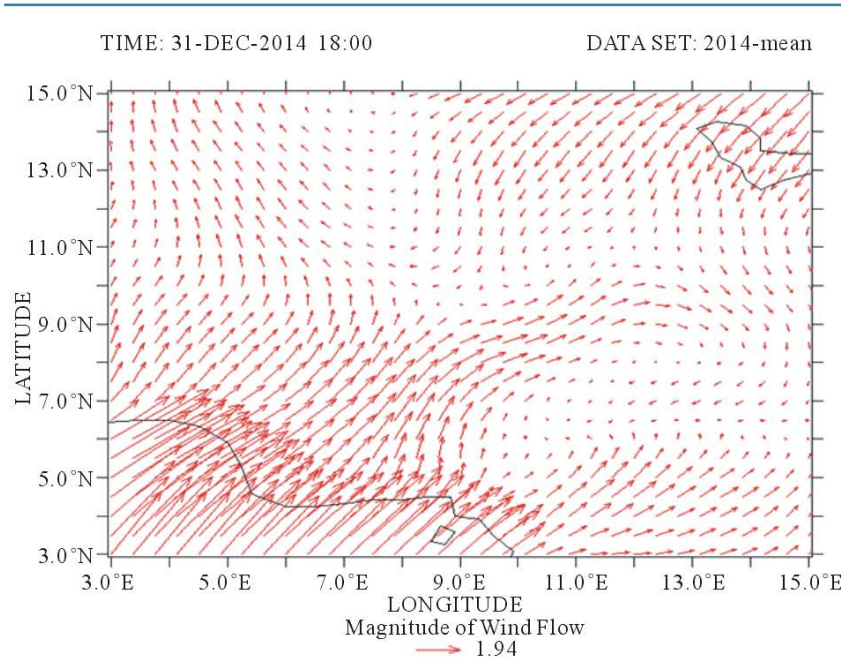

(a)
TIME: 31-DEC-2014 18:00

DATA SET: 2014-mean

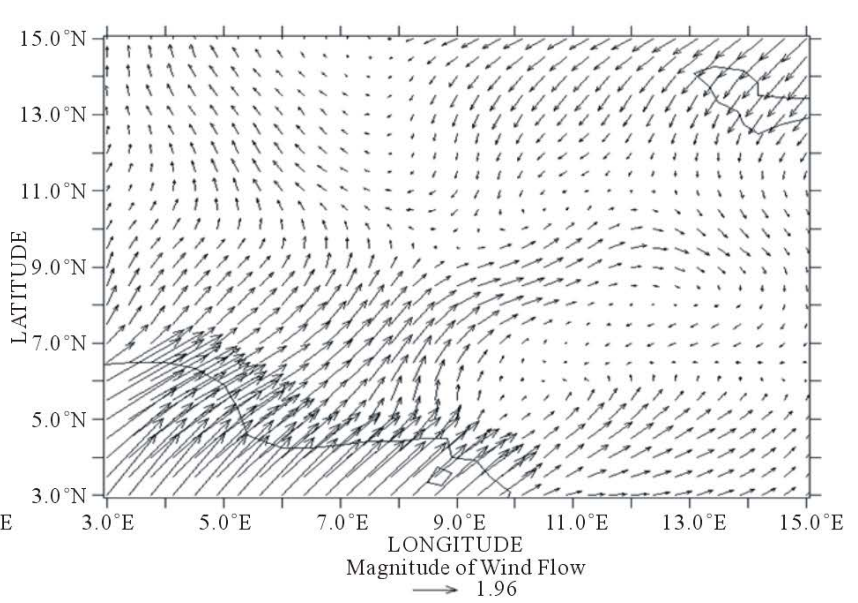

(b)

Figure 13. (a) Remapped wind field on $0.125^{\circ} \times 0.125^{\circ}$; (b) Actual wind field on $0.125^{\circ} \times 0.125^{\circ}$ grid resolution.

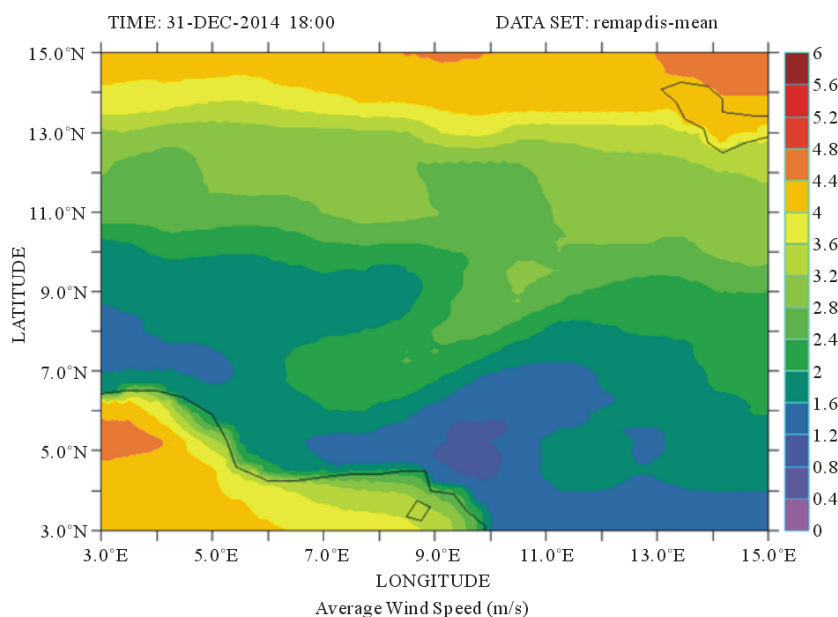

(a)

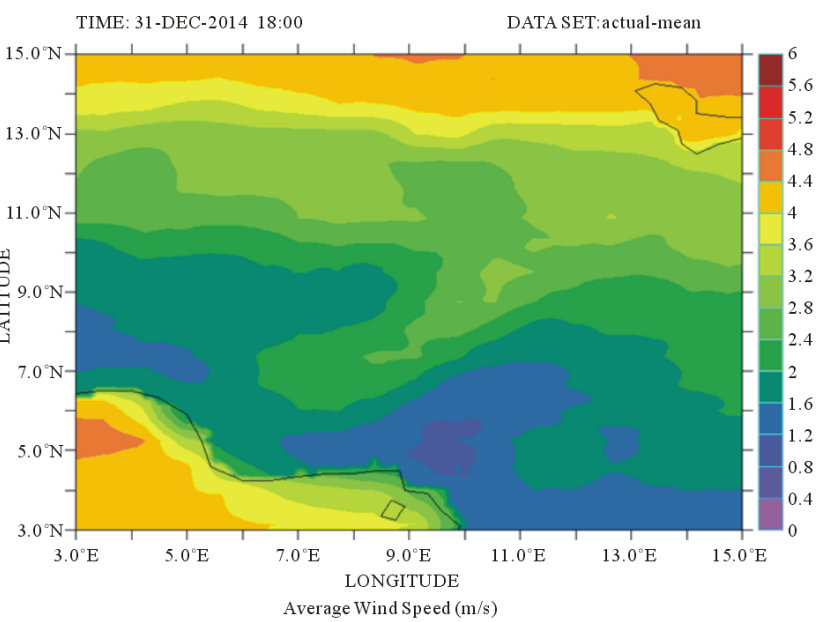

(b)

Figure 14. A 10-year wind speed chart of Nigeria on: (a) remapped and (b) actual wind fields at $0.125^{\circ} \times 0.125^{\circ}$ grid resolution.

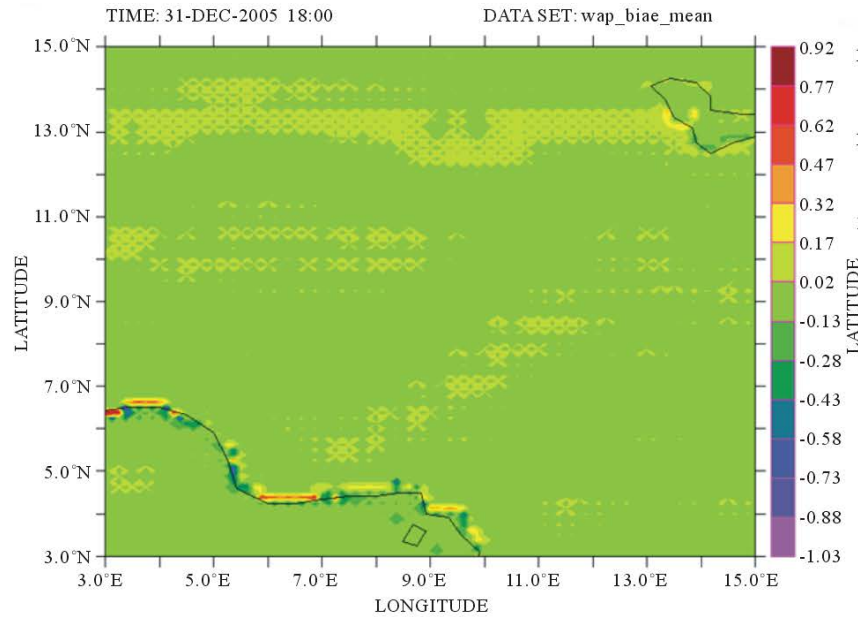

(a)

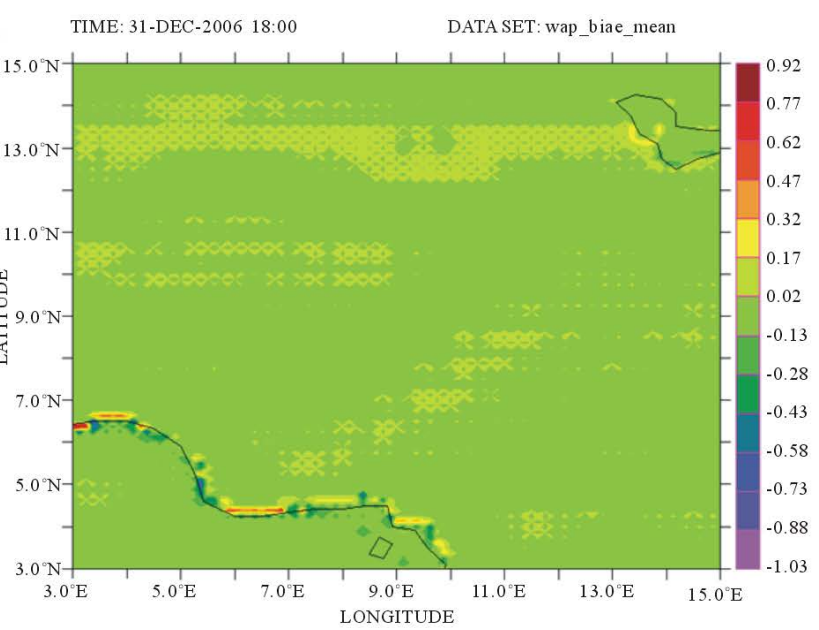

(b)

Figure 15. Annual mean wind speed biases (m/s) for (a) 2005 (b) 2006. 


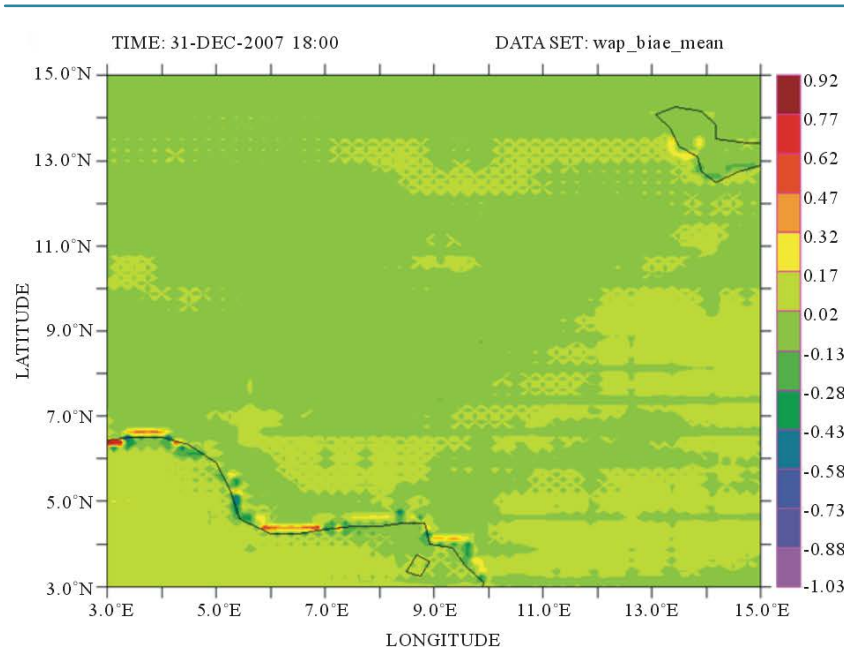

(a)

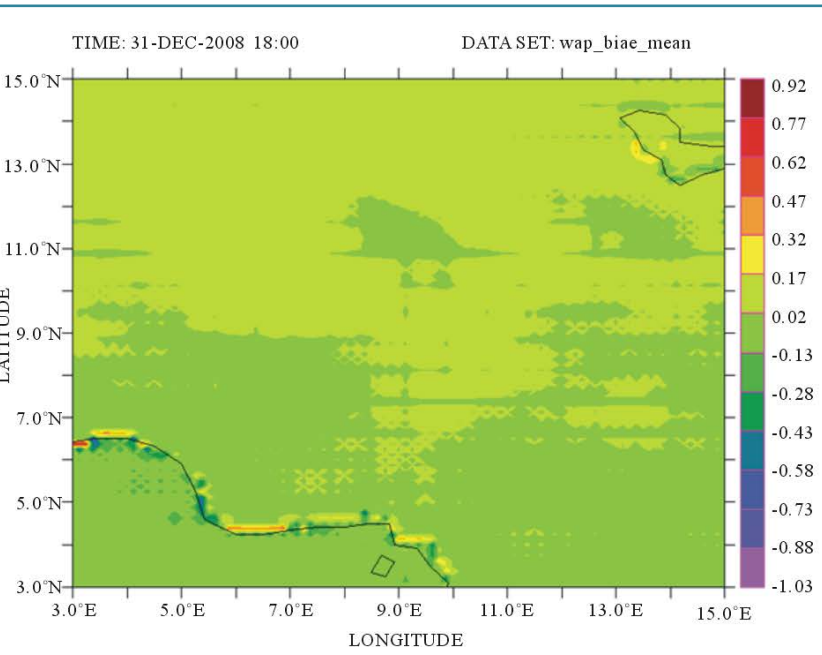

(b)

Figure 16. Annual mean wind speed biases (m/s) for (a) 2007 (b) 2008.

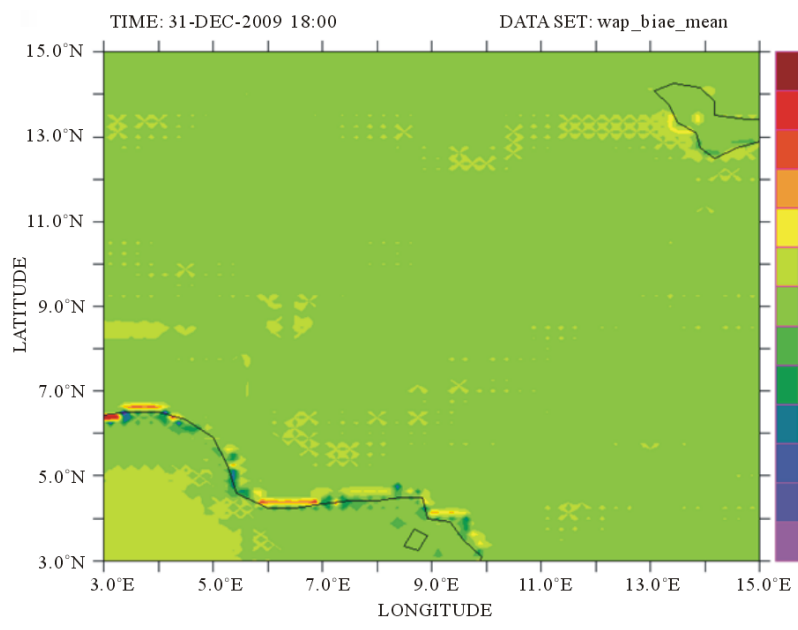

(a)

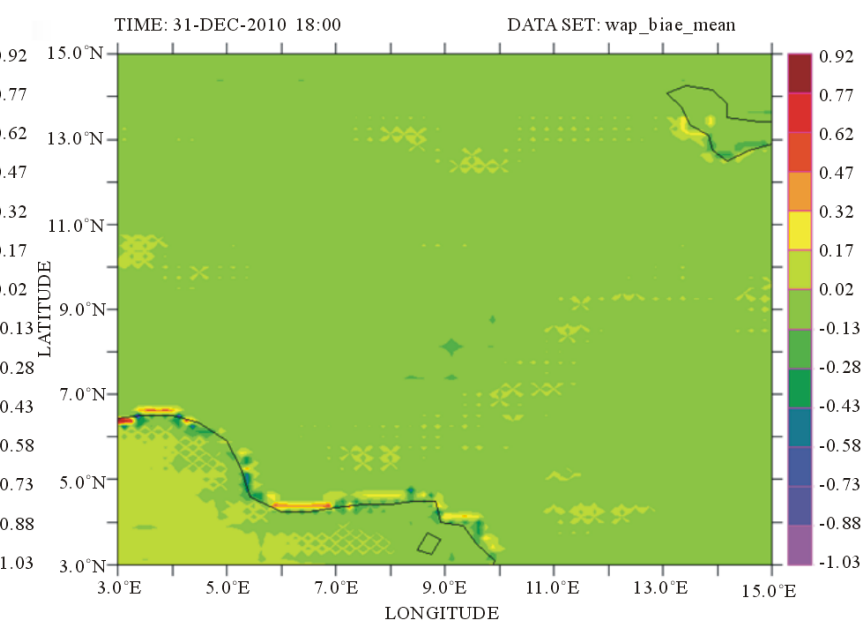

(b)

Figure 17. Annual mean wind speed biases (m/s) for (a) 2009 (b) 2010.

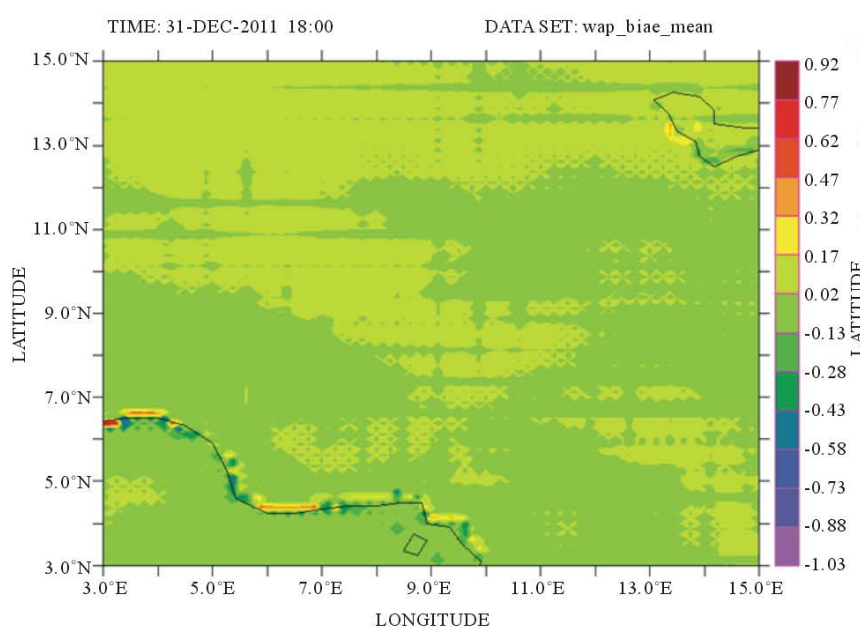

(a)

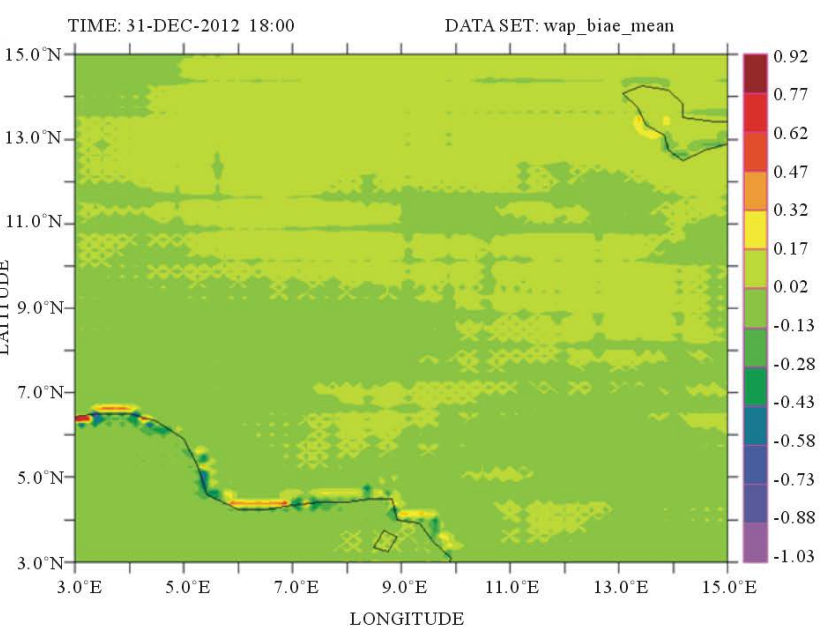

(b)

Figure 18. Annual mean wind speed biases (m/s) for (a) 2011 (b) 2012. 


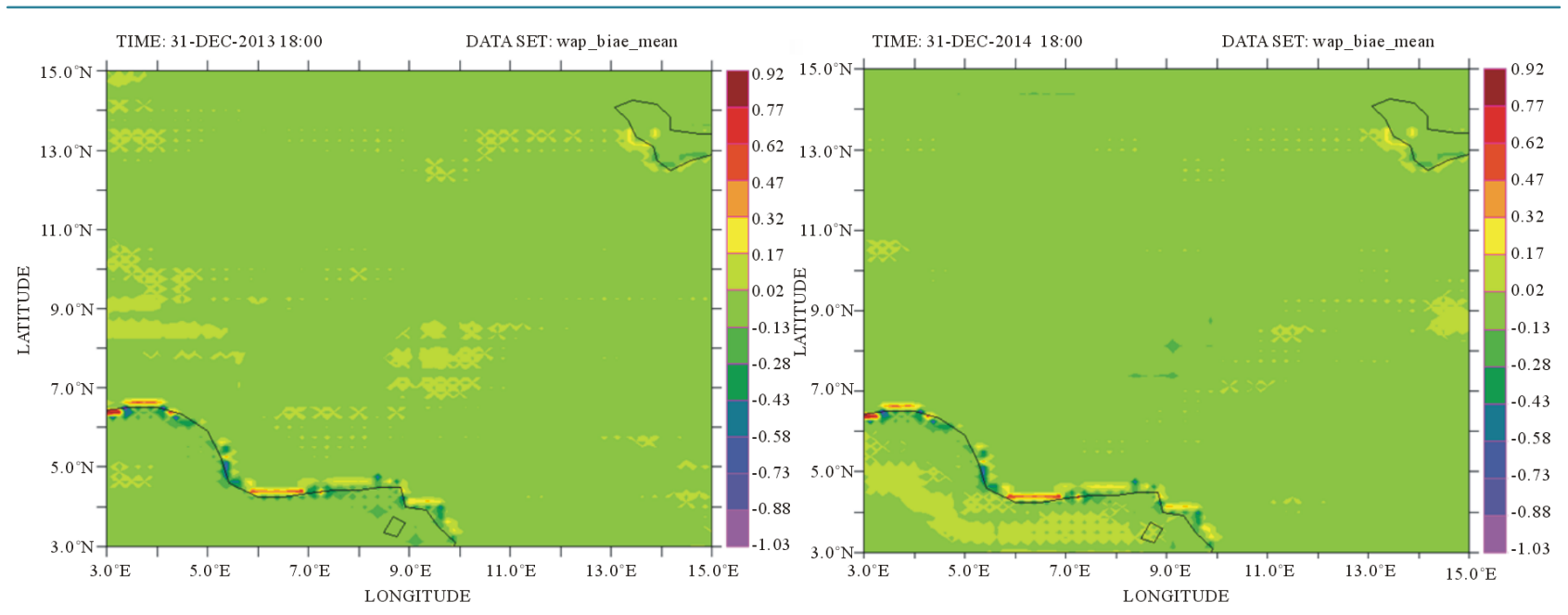

(a)

(b)

Figure 19. Annual mean wind speed biases (m/s) for (a) 2013 (b) 2014.

Given an estimated distance-weighted gridded wind speed value $k_{n}$ and the actual wind speed value $k$ at a $0.125^{\circ} \times 0.125^{\circ}$ grid resolution, the absolute error of the two gridded wind speed values is defined by the expression:

$$
\Delta x_{a}=\left|k_{n}-k\right|
$$

where $\Delta x_{a}$ is the absolute error of the two gridded wind speed values and the mean error $(\mathrm{m} / \mathrm{s})$ associated with the remapped wind field is defined by the expression:

$$
M E=k_{n}-k
$$

In addition, given an estimated distance-weighted averaging wind speed $k_{n}$ and the actual wind speed $k$ at $0.125^{\circ} \times 0.125^{\circ}$ grid resolution, the relative difference of the wind field is given by:

$$
\Delta x_{r}=\frac{k_{n}-k}{k}
$$

where $\Delta x_{r}$ is the relative difference of the two gridded wind speed values and the relative error in percentage (\%) associated with the remapped wind field is estimated from the given expression:

$$
R E=\frac{k_{n}-k}{k} * 100 \%
$$

Using Equations (3)-(6) above, the wind speed biases of the remapped field from the actual field are estimated for a period of 10 years (2005-2014). The estimated annual mean wind speed biases at a grid resolution of $0.125^{\circ} \times 0.125^{\circ}\left(n_{x}=97, n_{y}=97\right)$ are presented in Figures 15-19. In addition, Table 3 summarized the overall minimum $(\mathrm{m} / \mathrm{s})$, mean $(\mathrm{m} / \mathrm{s})$ and maximum $(\mathrm{m} / \mathrm{s})$ wind speed biases of the remapped wind field.

From the validation results of the remapped wind field starting from 00:00:00 UTC Jan-01, 2005 to 18:00:00 UTCDec-31, 2014, the remapped wind field approximated the wind close to the actual wind for a homogenous terrain. For complex terrains with surrounding tall buildings, the remapped wind field based on distance-weighted averaging produced a poor remapping and underestimated the magnitude of the wind flow. However, the remapped gridded field from a $0.25^{\circ} \times 0.25^{\circ}$ to $0.125^{\circ} \times 0.125^{\circ}$ grid resolution is a good reflection of the prevailing wind originated from the Gulf of Guinea, Chad and Niger when compared with the actual gridded field on $0.125^{\circ} \times 0.125^{\circ}$ grid resolution. Furthermore, the wind flow comparison for a 10 years period using gridded datasets on $0.25^{\circ} \times 0.25^{\circ}$ and $0.125^{\circ} \times 0.125^{\circ}$ resolutions is a significant step for identification of potential sites at wind regimes with no historical records/in situ measurements. Because of the limitation of ERA-reanalysis wind records in energy application, the development of state-of-the art mesoscale modeling over the geographical coordinates of the wind field should be considered. 


\subsection{Grid Interpolation of Gridded Wind Field and Comparisons with Synoptic Observations}

Bilinear interpolation was carried out on the remapped and actual wind fields on a grid resolution of $0.125^{\circ} \times$ $0.125^{\circ}\left(n_{x}=97, n_{y}=97\right)$ to obtain the gridded dataset for each synoptic station. To obtain the gridded datasets, the geographical coordinates of 18 stations in Nigeria was obtained from the World Meteorological Organization (WMO) list containing surface and upper-air weather stations' records for synoptic applications. Using each synoptic station coordinates, the gridded wind speed datasets at the surface layer was obtained performing a bilinear interpolation on the remapped and actual wind fields. The wind speed values of each synoptic station in daily temporal resolution of 00:00:00, 06:00:00, 12:00:00 and 18:00:00 UTC for the period of 10 years were obtained. The comparisons of the mean wind speeds of the interpolated synoptic stations from the remapped and actual wind field are presented in Figure 20.

Using Equations (7), (8) above, the minimum, mean and maximum wind speed discrepancies of the remapped field from the actual wind field are estimated as summarized in Table 3. In addition, the estimated wind speed discrepancies from the actual wind in terms of the mean error $(\mathrm{m} / \mathrm{s})$ and percentage error $(\%)$ for each synoptic

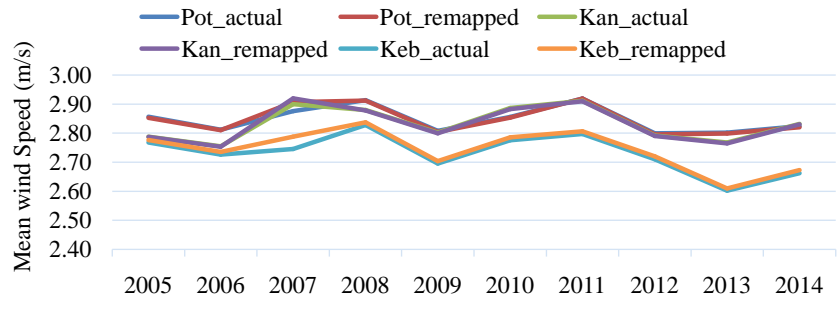

Years

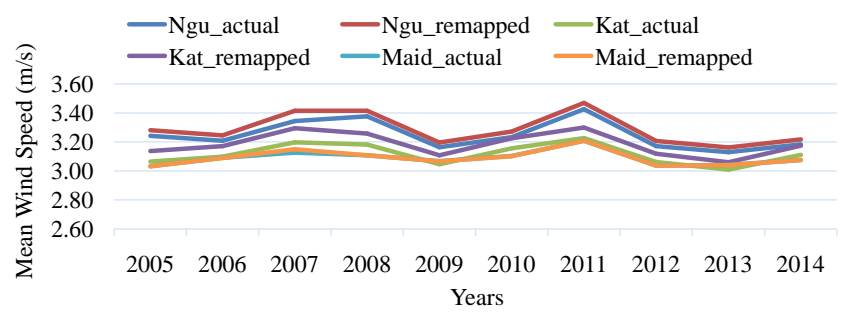

(b)

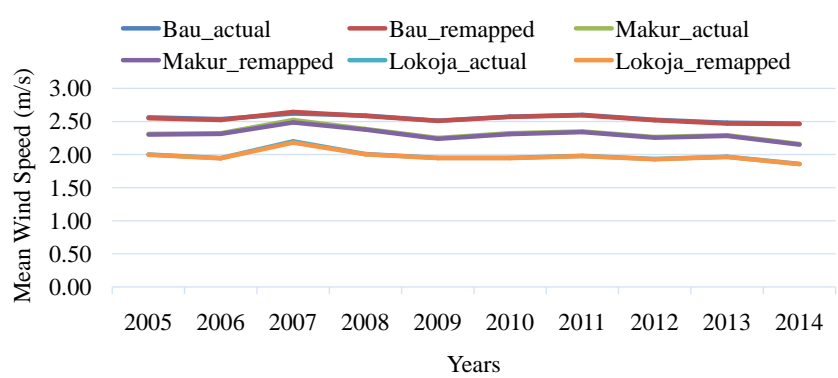

(a)
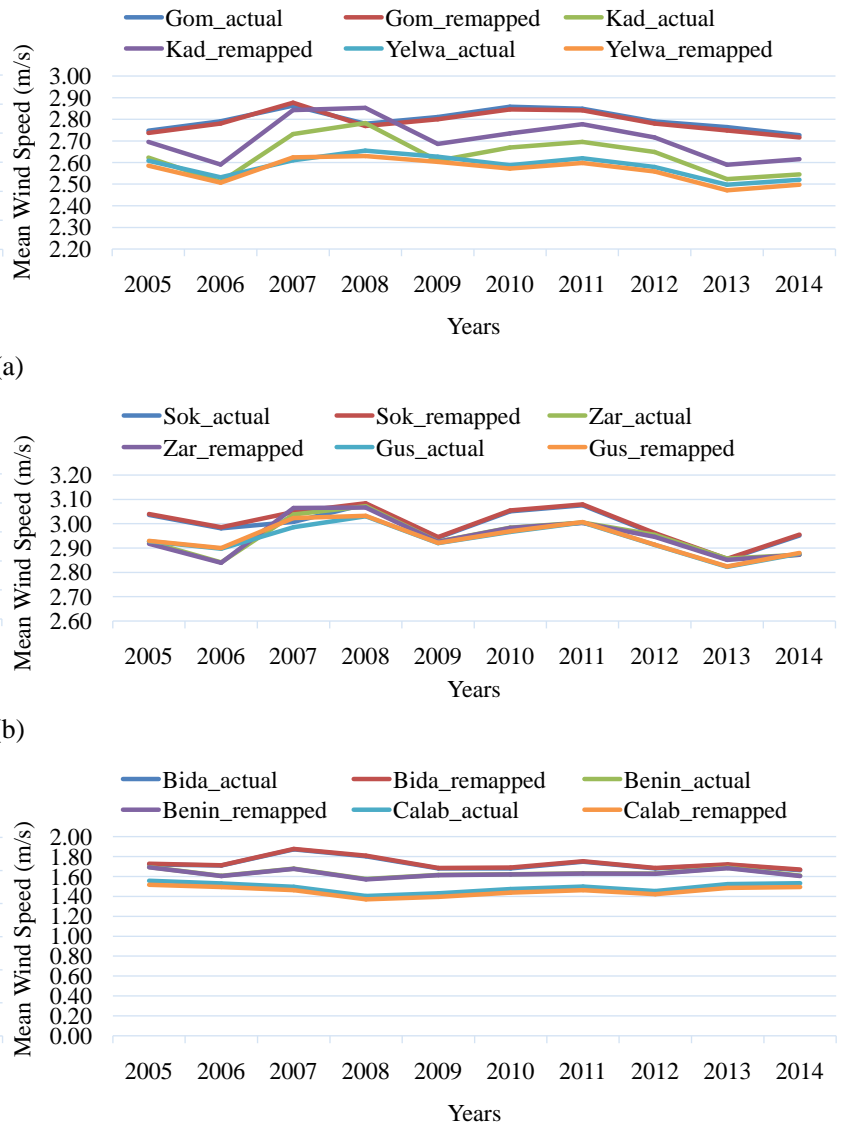

(c)

Figure 20. Comparisons of the mean wind speeds of remapped with actual synoptic stations.

Table 3. Summary of the minimum $(\mathrm{m} / \mathrm{s})$, mean $(\mathrm{m} / \mathrm{s})$ and maximum $(\mathrm{m} / \mathrm{s})$ wind speed biases of the remapped field.

\begin{tabular}{|c|c|c|c|c|c|c|c|c|c|c|c|}
\hline Error & 2005 & 2006 & 2007 & 2008 & 2009 & 2010 & 2011 & 2012 & 2013 & 2014 & Average \\
\hline Min & -3.048 & -1.580 & -1.846 & -3.903 & -2.619 & -2.410 & -2.236 & -2.283 & -2.602 & -4.628 & -2.716 \\
\hline Mean & -0.003 & -0.002 & 0.004 & -0.001 & -0.002 & -0.002 & -0.001 & -0.002 & -0.003 & 0.028 & 0.002 \\
\hline Max & 1.952 & 2.105 & 2.137 & 2.400 & 2.019 & 2.386 & 2.027 & 2.529 & 2.427 & 4.057 & 2.404 \\
\hline
\end{tabular}


station are summarized in Table 4. The results summarized in both tables are useful in evaluating the performance of the distance-weighted remapping of the wind field from one grid resolution to another at different geographical coordinates. From the estimated results, it can be seen that the remapped wind field approximated close to the actual wind field at flat terrain and the discrepancies increased with terrain elevations with contours.

Finally, the hourly surface wind observations from 18 synoptic stations in Nigeria obtained from the National Ocean and Atmospheric Administration (NOAA) are converted to surface monthly mean wind speed because of missing data points at different times and geographical locations. For comparisons, the minimum, mean and maximum wind speeds of each interpolated synoptic stations are plotted in Figures 21(a)-23(a), while the minimum, mean and maximum wind speeds for the surface observations are presented in Figures 21(b)-23(b). Table 5 summarized the annual minimum $(\mathrm{m} / \mathrm{s})$, mean $(\mathrm{m} / \mathrm{s})$ and maximum $(\mathrm{m} / \mathrm{s})$ surface wind speed observations for the synoptic stations. The comparisons of the ERA wind with the surface wind observations proved that the prevailing wind in Nigeria is higher than the reanalysis wind projection obtained from gridded datasets at resolution of $0.125^{\circ} \times 0.125^{\circ}$. However, the reanalysis wind simulation is essential in understanding the wind circulation in Nigeria especially at synoptic stations with missing or very poor historical wind records.

\section{Discussion}

The wind circulation within the remapped field studied for a period of 10 years. The wind circulation in terms of convergence and divergence at different geographical locations in Nigeria can be best understood overlaying Figures 4-13 on Figure 1(a), Figure 1(b). These figures explain the wind flow divergence and convergence at the wind field of coordinates $\lambda_{x}=3-15^{\circ} \mathrm{E}, \varphi_{y}=15-3^{\circ} \mathrm{N}$ on a grid resolution of $0.125^{\circ} \times 0.125^{\circ}$. In addition, the magnitude of wind flow covering the longitudinal and latitudinal direction of $3.0-15.0^{\circ} \mathrm{E}$ and $15.0-3.0^{\circ} \mathrm{N}$ has been graphically analysed using a 10 meter $U$ and V wind speed components at a daily timestamp of 00:00:00, 06:00:00, 12:00:00, and 18:00:00 UTC for period of 2005-2014. A strong wind emerged from the Gulf of Guinea, Chad and Niger into Nigeria, and is deflected by terrain elevations and surrounding tall buildings at different geographical locations within the wind field. Furthermore, the wind converged at some cities in the South-West and South-South regions of Nigeria, and a higher percentage of the wind flow is deflected towards neighbouring countries like Benin, Niger and Cameroun. As a result of the terrain elevation differences at geographical locations within the wind field, the magnitude of the wind flow decreases before reaching the South-West region like Lagos, Ogun, Osun, Oyo, Ondo and Ekiti States. These states have a very poor wind potential for energy conversion in the South-West region of Nigeria. The 18 synoptic stations owned by the Nigerian Meterological Agency (NIMET) and situated at different wind locations have been shown to be subjected to the influenced of the wind flow originated from Gulf of Guinea, Chad and Niger.

Nigeria is located within the northern Hemisphere, and the surface high pressure system in the northern Hemisphere has a clockwise rotation turning the wind outwardly from the highest pressure system towards the lowest pressure system. The pressure gradient force (pgf) causes the air parcel to diverge at the centre of the high pressure near the surface level, leading to sinking air in the centre of a high pressure system. This explains the wind flow in Northern Nigeria through: Maiduguri, Damaturu, Katsina, Sokoto, Nguru, Cashua, Hadejia, Birnin Kebbi and Nguru. In the South-West and South-East of Nigeria where there is wind convergence, the low pressure system has anticlockwise rotation and the wind turns inwardly towards the low pressure. These wind convergence at these cities cause air rising at the centre of the low pressure system near the ground, leading to cloud formation and precipitation occurrence.

The comparison of the mean wind speed chart of Nigeria for a period of 10 years is shown in Figure 14(a), Figure 14(b) while Figures 15-19 summarized graphically the annual mean wind speed biases of the remapped wind field on a grid resolution of $0.125^{\circ} \times 0.125^{\circ}$. In addition, Table 3 summarized the annual wind speed biases $(\mathrm{m} / \mathrm{s})$ of the remapped field from the actual field for the same period of 10 years. From the comparisons of the figures and table, the wind speed biases were very small at geographical locations with a smooth or flat terrain and increased significantly at locations with high terrain elevations.

The remapped wind field based on the distance-weighted averaging has been interpolated bilinearly for the identification of potential wind sites in Nigeria. The magnitude of wind flow differs from one geographical location to another as seen in Figures 4-13. The geographical locations such as Sokoto, Katsina, Nguru, Gusau, Birnin Kebbi, Maiduguri, Zaria, Potiskum, Cashua, Hadejia and Kaduna have a large-scale wind potential for 


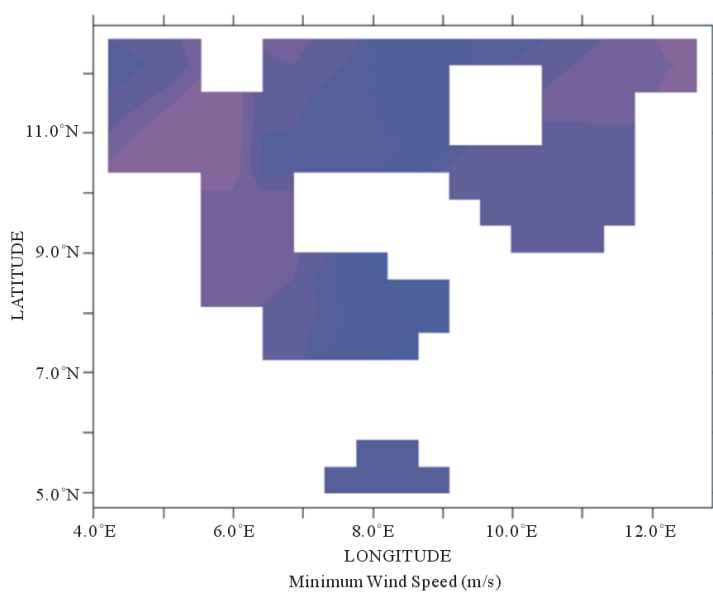

(a)
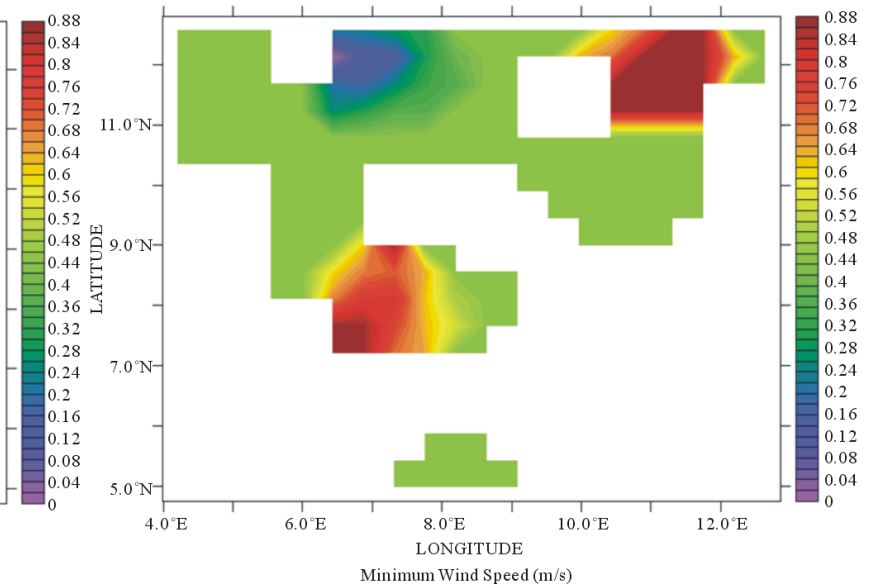

(b)

Figure 21. Comparisons of the minimum wind speeds for 18 synoptic stations using: (a) ERA wind simulations; (b) Surface wind observations.

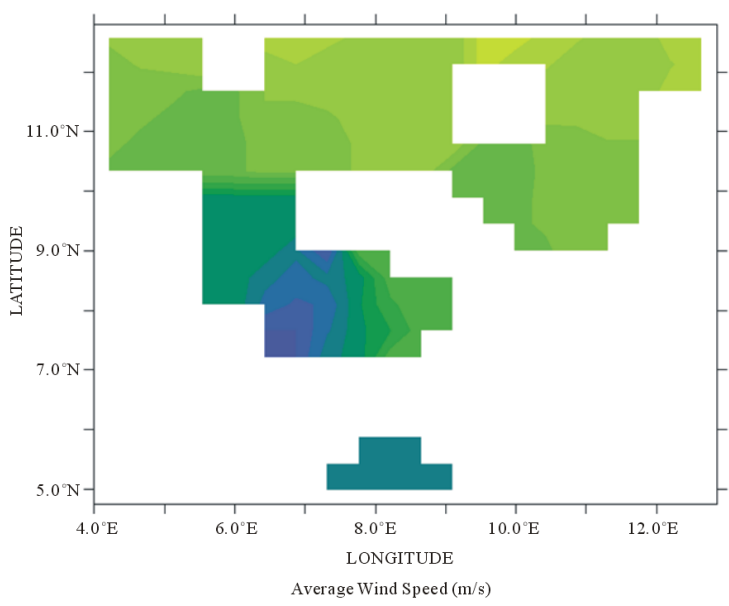

(a)
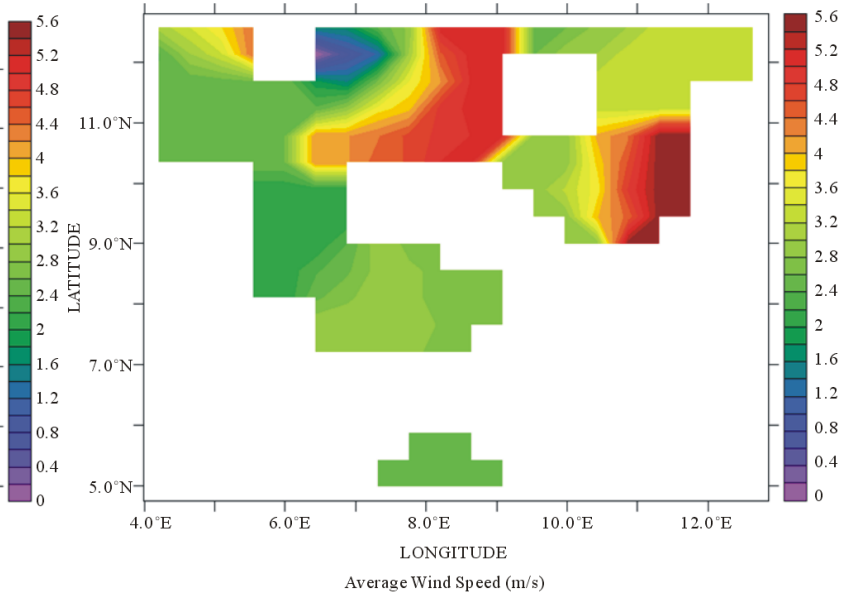

(b)

Figure 22. Comparisons of the mean wind speeds for 18 synoptic stations using: (a) ERA wind simulations; (b) Surface wind observations.

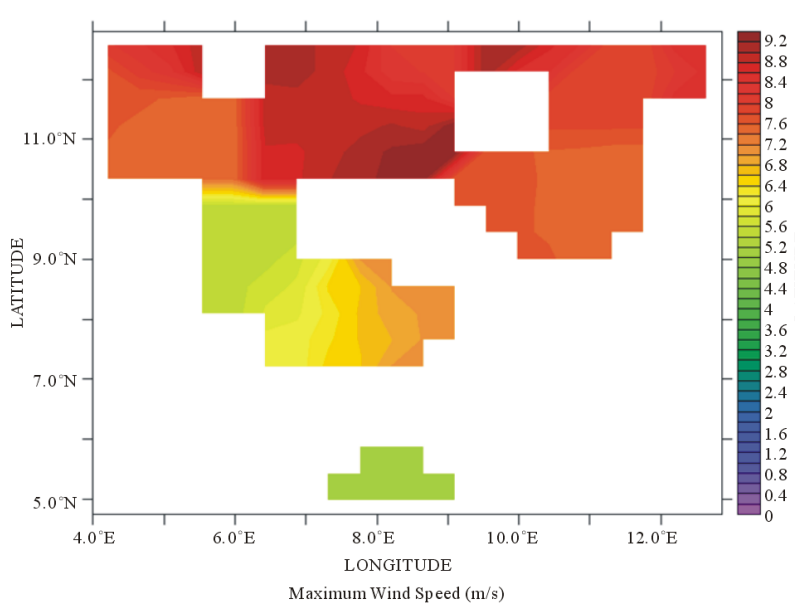

(a)

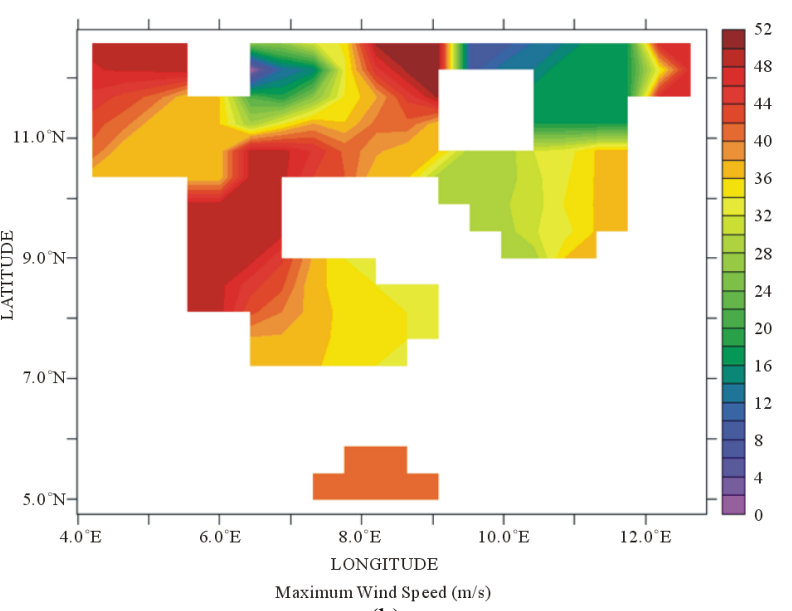

(b)

Figure 23. Comparisons of the maximum wind speeds for 18 synoptic stations using: (a) ERA wind simulations; (b) Surface wind observations. 
Table 4. Annual mean wind errors (m/s) and percentage errors (\%) for 18 synoptic stations on a grid resolution of $0.125^{\circ} \times$ $0.125^{\circ}$.

\begin{tabular}{|c|c|c|c|c|c|c|c|c|c|c|c|}
\hline State & & 2005 & 2006 & 2007 & 2008 & 2009 & 2010 & 2011 & 2012 & 2013 & 2014 \\
\hline \multirow{2}{*}{ Ngu. } & $\mathrm{ME}(\mathrm{m} / \mathrm{s})$ & 0.038 & 0.037 & 0.030 & 0.092 & 0.012 & 0.001 & 0.054 & 0.068 & 0.011 & -0.005 \\
\hline & PE (\%) & 1.167 & 1.147 & 0.885 & 2.698 & 0.374 & 0.043 & 1.555 & 2.122 & 0.355 & -0.162 \\
\hline \multirow{2}{*}{ Kat. } & $\mathrm{ME}(\mathrm{m} / \mathrm{s})$ & 0.073 & 0.072 & 0.066 & 0.107 & 0.033 & 0.042 & 0.090 & 0.094 & 0.018 & 0.023 \\
\hline & PE (\%) & 2.330 & 2.273 & 1.991 & 3.292 & 1.064 & 1.303 & 2.718 & 3.012 & 0.590 & 0.716 \\
\hline \multirow{2}{*}{ Maid. } & $\mathrm{ME}(\mathrm{m} / \mathrm{s})$ & -0.001 & -0.001 & 0.011 & 0.012 & -0.004 & -0.014 & 0.006 & 0.013 & -0.018 & -0.013 \\
\hline & PE (\%) & -0.020 & -0.035 & 0.344 & 0.398 & -0.117 & -0.458 & 0.199 & 0.414 & -0.603 & -0.410 \\
\hline \multirow{2}{*}{ Sok. } & $\mathrm{ME}(\mathrm{m} / \mathrm{s})$ & 0.003 & 0.004 & -0.019 & 0.059 & -0.032 & -0.037 & 0.034 & 0.035 & -0.022 & -0.038 \\
\hline & PE (\%) & 0.112 & 0.129 & -0.628 & 1.912 & -1.099 & -1.211 & 1.113 & 1.193 & -0.778 & -1.301 \\
\hline \multirow{2}{*}{ Zar. } & $\mathrm{ME}(\mathrm{m} / \mathrm{s})$ & -0.010 & -0.006 & -0.047 & 0.064 & -0.034 & -0.056 & 0.016 & 0.037 & -0.041 & -0.056 \\
\hline & PE (\%) & -0.344 & -0.211 & -1.523 & 2.097 & -1.178 & -1.886 & 0.546 & 1.270 & -1.443 & -1.965 \\
\hline \multirow{2}{*}{ Gus. } & $\mathrm{ME}(\mathrm{m} / \mathrm{s})$ & 0.002 & 0.003 & -0.029 & 0.067 & -0.039 & -0.043 & 0.030 & 0.046 & -0.031 & -0.047 \\
\hline & PE (\%) & 0.074 & 0.119 & -0.963 & 2.202 & -1.321 & -1.444 & 1.010 & 1.583 & -1.081 & -1.615 \\
\hline \multirow{2}{*}{ Pot. } & $\mathrm{ME}(\mathrm{m} / \mathrm{s})$ & -0.004 & -0.001 & -0.004 & 0.037 & -0.019 & -0.025 & 0.006 & 0.016 & -0.019 & -0.032 \\
\hline & PE (\%) & -0.137 & -0.048 & -0.153 & 1.256 & -0.662 & -0.886 & 0.207 & 0.576 & -0.678 & -1.135 \\
\hline \multirow{2}{*}{ Kan. } & $\mathrm{ME}(\mathrm{m} / \mathrm{s})$ & -0.003 & -0.004 & 0.000 & 0.011 & -0.019 & -0.017 & 0.003 & 0.021 & -0.034 & -0.030 \\
\hline & PE (\%) & -0.108 & -0.138 & 0.011 & 0.383 & -0.685 & -0.602 & 0.106 & 0.760 & -1.225 & -1.076 \\
\hline \multirow{2}{*}{ Keb. } & $\mathrm{ME}(\mathrm{m} / \mathrm{s})$ & 0.008 & 0.010 & -0.014 & 0.058 & -0.017 & -0.022 & 0.038 & 0.030 & -0.009 & -0.018 \\
\hline & PE (\%) & 0.294 & 0.353 & -0.490 & 2.052 & -0.646 & -0.808 & 1.349 & 1.086 & -0.339 & -0.671 \\
\hline \multirow{2}{*}{ Gom. } & $\mathrm{ME}(\mathrm{m} / \mathrm{s})$ & -0.011 & -0.010 & -0.019 & 0.039 & -0.051 & -0.015 & -0.006 & 0.024 & -0.042 & -0.029 \\
\hline & PE (\%) & -0.390 & -0.354 & -0.669 & 1.397 & -1.805 & -0.538 & -0.203 & 0.846 & -1.542 & -1.076 \\
\hline \multirow{2}{*}{ Kad. } & $\mathrm{ME}(\mathrm{m} / \mathrm{s})$ & 0.016 & 0.018 & -0.029 & 0.110 & -0.027 & -0.044 & 0.047 & 0.062 & -0.009 & -0.039 \\
\hline & PE (\%) & 0.580 & 0.705 & -1.009 & 3.843 & -1.008 & -1.601 & 1.676 & 2.271 & -0.348 & -1.507 \\
\hline \multirow{2}{*}{ Yelwa } & $\mathrm{ME}(\mathrm{m} / \mathrm{s})$ & -0.023 & -0.024 & -0.052 & 0.039 & -0.054 & -0.032 & -0.003 & -0.012 & -0.037 & -0.044 \\
\hline & PE (\%) & -0.895 & -0.970 & -1.994 & 1.493 & -2.089 & -1.236 & -0.122 & -0.463 & -1.486 & -1.777 \\
\hline \multirow{2}{*}{ Bau. } & $\mathrm{ME}(\mathrm{m} / \mathrm{s})$ & -0.016 & -0.012 & 0.001 & 0.010 & -0.026 & -0.009 & 0.000 & 0.024 & -0.037 & -0.016 \\
\hline & PE (\%) & -0.615 & -0.476 & 0.043 & 0.381 & -1.028 & -0.345 & -0.014 & 0.937 & -1.480 & -0.659 \\
\hline \multirow{2}{*}{ Makur. } & $\mathrm{ME}(\mathrm{m} / \mathrm{s})$ & -0.011 & -0.012 & -0.045 & 0.021 & -0.001 & -0.082 & 0.021 & -0.001 & 0.014 & -0.079 \\
\hline & PE (\%) & -0.469 & -0.516 & -1.811 & 0.894 & -0.063 & -3.567 & 0.897 & -0.028 & 0.602 & -3.693 \\
\hline \multirow{2}{*}{ Lokoja } & $\mathrm{ME}(\mathrm{m} / \mathrm{s})$ & -0.005 & -0.003 & 0.010 & -0.005 & 0.011 & -0.021 & -0.008 & 0.004 & 0.009 & -0.053 \\
\hline & PE (\%) & -0.261 & -0.155 & 0.466 & -0.243 & 0.545 & -1.089 & -0.382 & 0.192 & 0.478 & -2.875 \\
\hline \multirow{2}{*}{ Bida } & $\mathrm{ME}(\mathrm{m} / \mathrm{s})$ & -0.040 & -0.038 & -0.013 & -0.032 & -0.051 & -0.035 & -0.039 & -0.025 & -0.043 & -0.041 \\
\hline & PE (\%) & -2.643 & -2.534 & -0.880 & -2.347 & -3.639 & -2.444 & -2.675 & -1.7357 & -2.897 & -2.757 \\
\hline \multirow{2}{*}{ Benin } & $\mathrm{ME}(\mathrm{m} / \mathrm{s})$ & -0.003 & -0.003 & 0.015 & -0.017 & 0.000 & -0.003 & 0.003 & -0.003 & -0.003 & -0.020 \\
\hline & PE (\%) & -0.200 & -0.209 & 0.902 & -1.062 & 0.000 & -0.160 & 0.159 & -0.188 & -0.161 & -1.229 \\
\hline \multirow{2}{*}{ Calab. } & $\mathrm{ME}(\mathrm{m} / \mathrm{s})$ & -0.040 & -0.038 & -0.013 & -0.032 & -0.051 & -0.035 & -0.039 & -0.025 & -0.043 & -0.041 \\
\hline & PE (\%) & -2.643 & -2.534 & -0.880 & -2.347 & -3.640 & -2.444 & -2.675 & -1.736 & -2.897 & -2.757 \\
\hline
\end{tabular}


Table 5. Summary of the minimum $(\mathrm{m} / \mathrm{s})$, mean $(\mathrm{m} / \mathrm{s})$ and maximum $(\mathrm{m} / \mathrm{s})$ wind speed observations for 18 synoptic stations.

\begin{tabular}{|c|c|c|c|c|c|c|c|c|c|c|c|}
\hline State & & 2005 & 2006 & 2007 & 2008 & 2009 & 2010 & 2011 & 2012 & 2013 & 2014 \\
\hline \multirow{3}{*}{ Ngu. } & Min & - & 0.00 & 0.00 & 0.00 & 0.00 & 0.00 & 0.00 & - & 0.00 & - \\
\hline & Mean & - & 1.12 & 0.45 & 2.17 & 2.46 & 1.92 & 1.04 & - & 2.01 & - \\
\hline & Max & - & 2.68 & 0.89 & 5.81 & 6.26 & 4.92 & 2.68 & - & 4.03 & 8.94 \\
\hline \multirow{3}{*}{ Kat. } & Min & 0.89 & 0.00 & - & 0.00 & 0.00 & 0.00 & 0.00 & 0.00 & 0.00 & 0.00 \\
\hline & Mean & 2.06 & 4.60 & - & 3.81 & 3.42 & 2.51 & 2.55 & 2.75 & 3.16 & 2.60 \\
\hline & Max & 4.92 & 9.39 & - & 9.84 & 48.75 & 11.18 & 11.18 & 6.71 & 48.75 & 29.96 \\
\hline \multirow{3}{*}{ Maid. } & Min & 0.00 & 0.00 & - & 0.00 & 0.00 & 0.00 & 0.00 & 4.47 & 0.00 & - \\
\hline & Mean & 3.44 & 4.96 & - & 4.19 & 2.62 & 2.40 & 2.81 & 5.22 & 3.94 & - \\
\hline & Max & 30.86 & 36.23 & 3.58 & 7.16 & 10.29 & 30.86 & 7.60 & 6.71 & 14.76 & - \\
\hline \multirow{3}{*}{ Sok. } & Min & 0.00 & 0.00 & 2.68 & 0.00 & 0.00 & 0.00 & 0.00 & 0.00 & 0.00 & 0.00 \\
\hline & Mean & 4.19 & 4.48 & 8.15 & 5.09 & 3.51 & 3.57 & 4.05 & 3.18 & 3.77 & 2.89 \\
\hline & Max & 28.16 & 10.73 & 48.75 & 11.63 & 46.52 & 16.10 & 10.29 & 9.39 & 49.20 & 11.63 \\
\hline \multirow{3}{*}{ Zar. } & Min & - & 0.00 & 0.00 & 0.00 & 0.00 & 0.00 & 0.00 & 0.00 & 0.00 & 0.00 \\
\hline & Mean & - & 3.28 & 3.89 & 3.47 & 2.82 & 3.57 & 4.30 & 6.06 & 4.27 & 4.18 \\
\hline & Max & 9.84 & 34.44 & 16.55 & 20.13 & 12.97 & 15.21 & 12.08 & 12.97 & 36.23 & 17.89 \\
\hline \multirow{3}{*}{ Gus. } & Min & - & - & - & - & - & - & - & - & - & - \\
\hline & Mean & - & - & - & - & - & - & - & - & - & - \\
\hline & Max & - & - & - & - & - & - & - & - & - & - \\
\hline \multirow{3}{*}{ Pot. } & Min & - & 0.00 & 3.13 & 0.00 & 0.00 & 0.00 & 0.00 & 0.00 & 0.00 & 0.00 \\
\hline & Mean & - & 3.37 & 5.93 & 3.60 & 3.53 & 2.99 & 2.75 & 2.71 & 3.15 & 3.40 \\
\hline & Max & - & 17.89 & 7.16 & 7.60 & 7.60 & 9.84 & 6.26 & 6.26 & 4.92 & 14.31 \\
\hline \multirow{3}{*}{ Kan. } & Min & 0.00 & 0.00 & 0.00 & 0.00 & 0.00 & 0.00 & 0.00 & 0.00 & 0.00 & 0.00 \\
\hline & Mean & 4.53 & 4.93 & 5.74 & 4.77 & 4.75 & 5.05 & 4.74 & 4.61 & 3.71 & 4.86 \\
\hline & Max & 21.02 & 20.13 & 15.21 & 30.86 & 30.86 & 30.86 & 50.54 & 30.86 & 46.51 & 30.86 \\
\hline \multirow{3}{*}{ Keb. } & Min & - & - & - & - & - & - & - & - & - & - \\
\hline & Mean & 2.96 & 2.77 & 2.65 & 2.21 & 2.13 & 2.23 & 2.34 & - & - & - \\
\hline & Max & 15.21 & 30.86 & 47.85 & 41.14 & 16.99 & 16.99 & 15.21 & - & - & - \\
\hline \multirow{3}{*}{ Gom. } & Min & - & - & - & - & - & - & - & 2.24 & 0.00 & 0.00 \\
\hline & Mean & - & - & - & - & - & - & - & 4.92 & 4.92 & 4.51 \\
\hline & Max & - & - & - & - & - & - & - & 9.39 & 36.23 & 35.33 \\
\hline \multirow{3}{*}{ Kad. } & Min & 0.00 & 0.00 & 0.00 & 0.00 & 0.00 & 0.00 & 0.00 & 0.00 & 0.00 & 0.00 \\
\hline & Mean & 3.46 & 3.64 & 3.91 & 3.18 & 2.49 & 3.12 & 3.07 & 3.29 & 2.89 & 3.22 \\
\hline & Max & 22.81 & 48.75 & 11.18 & 15.21 & 10.29 & 30.86 & 15.21 & 46.51 & 34.88 & 30.86 \\
\hline
\end{tabular}




\begin{tabular}{|c|c|c|c|c|c|c|c|c|c|c|c|}
\hline & Min & - & - & - & 0.00 & 0.00 & 0.00 & 0.00 & 0.00 & 0.00 & 0.00 \\
\hline \multirow[t]{3}{*}{ Yelwa } & Mean & - & - & - & 2.43 & 2.90 & 2.31 & 2.63 & 2.00 & 1.80 & 1.46 \\
\hline & Max & - & - & - & 36.23 & 8.05 & 6.71 & 12.08 & 28.62 & 12.97 & 6.26 \\
\hline & Min & 0.00 & 0.00 & 0.00 & 0.00 & 0.00 & 0.00 & 0.00 & 0.00 & 0.00 & - \\
\hline \multirow[t]{3}{*}{ Bau. } & Mean & 1.73 & 1.46 & 0.87 & 1.20 & 0.83 & 1.05 & 1.56 & 1.17 & 1.16 & - \\
\hline & Max & 20.57 & 7.16 & 3.13 & 28.62 & 7.60 & 8.05 & 12.97 & 7.60 & 4.47 & - \\
\hline & Min & 0.00 & 0.00 & 0.00 & 0.00 & 0.00 & 0.00 & 0.00 & 0.00 & 0.00 & 0.00 \\
\hline \multirow[t]{3}{*}{ Makur. } & Mean & 3.12 & 2.64 & 2.80 & 2.46 & 2.25 & 2.33 & 1.98 & 1.75 & 2.20 & 1.65 \\
\hline & Max & 9.39 & 11.63 & 9.39 & 8.50 & 13.42 & 33.10 & 8.05 & 6.71 & 33.99 & 31.75 \\
\hline & Min & 0.00 & - & 0.00 & 0.00 & 0.00 & 0.00 & 0.00 & 0.00 & 0.00 & 0.00 \\
\hline \multirow[t]{3}{*}{ Lokoja } & Mean & 1.93 & - & 1.36 & 1.18 & 1.59 & 1.57 & 1.25 & 1.68 & 1.53 & 1.59 \\
\hline & Max & 5.81 & - & 4,03 & 8.05 & 8.05 & 9.84 & 7.60 & 37.57 & 7.60 & 4.92 \\
\hline & Min & - & - & 0.00 & 0.00 & 0.00 & 0.00 & 0.00 & 0.00 & 0.00 & 0.00 \\
\hline \multirow[t]{3}{*}{ Bida } & Mean & - & - & 1.76 & 1.71 & 1.95 & 2.00 & 1.94 & 1.61 & 1.82 & 1.89 \\
\hline & Max & - & - & 4.03 & 12.97 & 48.83 & 48.30 & 4.92 & 8.05 & 42.93 & 9.39 \\
\hline & Min & - & 0.00 & 0.00 & 0.00 & 0.00 & 0.00 & 0.00 & 0.00 & 0.00 & 0.00 \\
\hline \multirow[t]{3}{*}{ Benin } & Mean & - & 1.85 & 2.39 & 1.82 & 2.10 & 2.22 & 1.75 & 2.28 & 2.14 & 2.93 \\
\hline & Max & - & 28.18 & 45.51 & 7.16 & 9.39 & 9.84 & 15.21 & 7.16 & 36.23 & 30.86 \\
\hline & Min & 0.00 & 0.00 & 0.00 & 0.00 & 0.00 & 0.00 & 0.00 & 0.00 & 0.00 & 0.00 \\
\hline \multirow[t]{2}{*}{ Calab. } & Mean & 2.57 & 2.73 & 0.96 & 2.21 & 2.11 & 1.99 & 2.16 & 2.08 & 1.58 & 1.53 \\
\hline & Max & 12.52 & 8.94 & 3.13 & 41.14 & 25.49 & 30.86 & 30.86 & 9.39 & 33.54 & 30.86 \\
\hline
\end{tabular}

grid-tie energy application at a much higher altitude, while Gombe, Bauchi and Minna have fair wind prevalence while wind convergence locations such as Abuja and Bida and South-West Nigeria (Lagos, Ogun, Oyo, Osun, Ekiti and Ondo states) have a very poor wind potential and is classified as a very low wind region. The wind flow study at this poor region using ERA-Interim wind dataset agrees with Fadare [24] classification of Ibadan city as a low wind energy region.

Table 5 summarized the minimum, mean and maximum wind speeds for 18 synoptic stations derived from surface wind observations. The following wind potential locations were identified based on the 10 years wind flow study: Bauchi (Bau.), Gombe (Gom.), Gusau (Gus.), Kaduna (Kad.), Kano (Kan.), Katsina (Kat.), Kebbi (Keb.), Maiduguri (Mad.), Nguru (Ngu.), Potiskum (Pot.), Sokoto (Sok.) and Zaria (Zar.). The wind locations such as Kaduna, Zaria, Bauchi, Katsina, Kano, Nguru, Potiskum and Gombe in northern Nigeria have terrain elevations at a 642.0, 664.0, 609.0, 506.0, 472.0, 344.0, 414.0 and $505.0 \mathrm{~m}$ above sea level, respectively. Other northern locations with synoptic stations benefitting from the same wind circulation are: Jos in Plateau state (1285.0 m), Minna (260.0 m) and Bida $(143.0 \mathrm{~m})$ in Niger state, Nnamdi Azikiwe in Abuja (342.0 m), Sokoto (302.0 m), Gusau (469.0 m), Birnin Kebbi $(220.0 \mathrm{~m}$ ) and Maiduguri $(354.0 \mathrm{~m})$. The local topography (such as surface roughness and terrain elevation) was expected to influence the wind direction at different locations causing resistance and deflection to the wind flow. Hence high wind speed discrepancies were observed at geographical locations with a complex terrain. For example, the direction of wind flow in Kastina and Kano are similar (Figure 24(b) and Figure 24(h)), while other synoptic stations experienced little or high wind deflection depending on the terrain elevation of the wind location. This applies to the wind flow originated at Gulf of Guinea into the South-West region of Nigeria as deflected toward the Benin Republic, Northern Nigeria as well as some cities in Cameroon. Lagos in the South-West region is a congested and commerical state in Nigeria with 


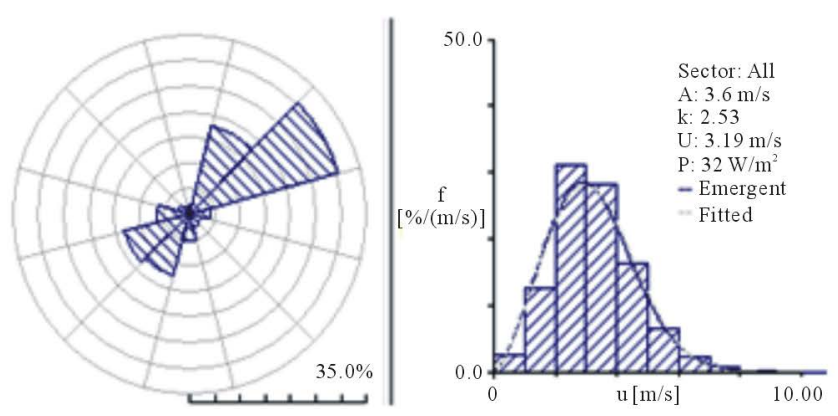

(a)
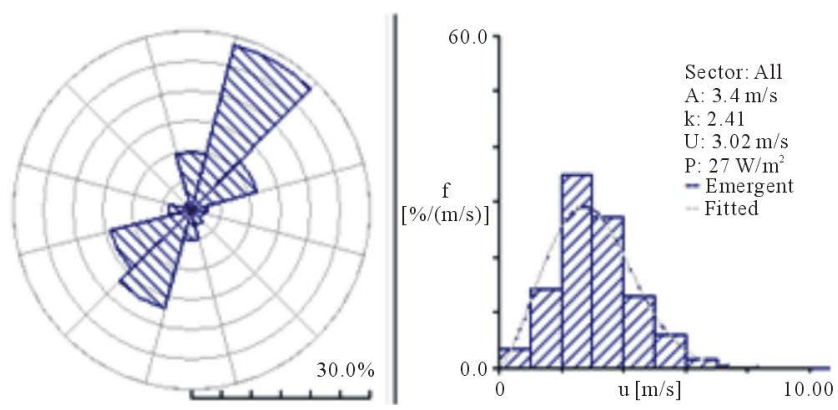

(c)
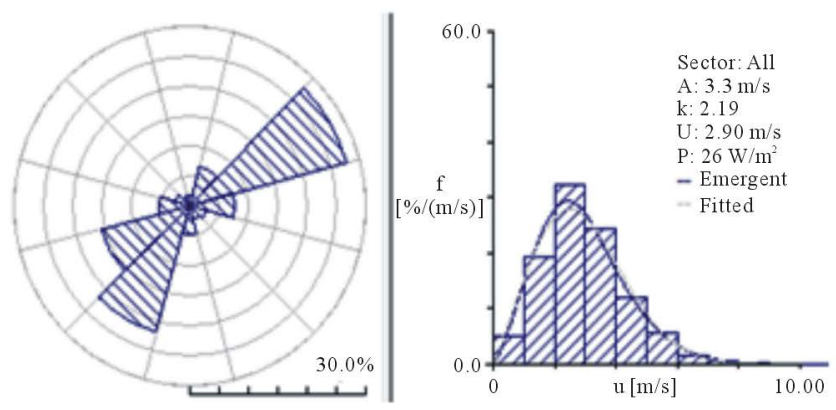

(e)
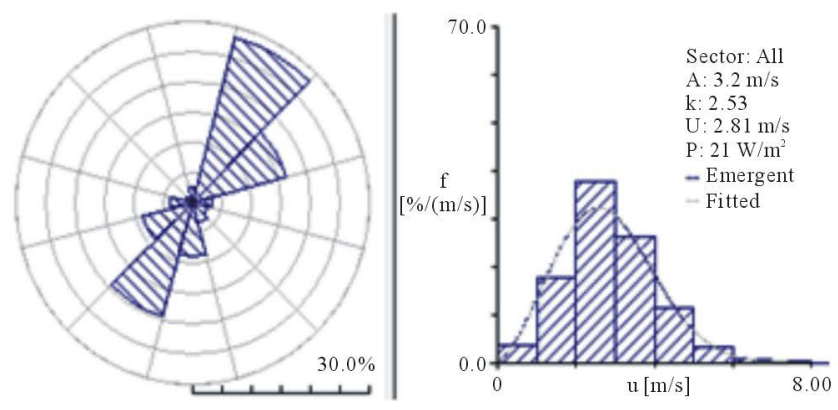

(g)
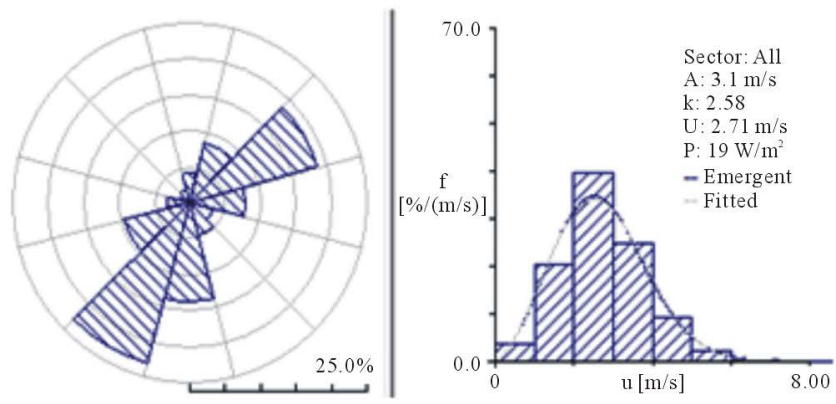

(i)
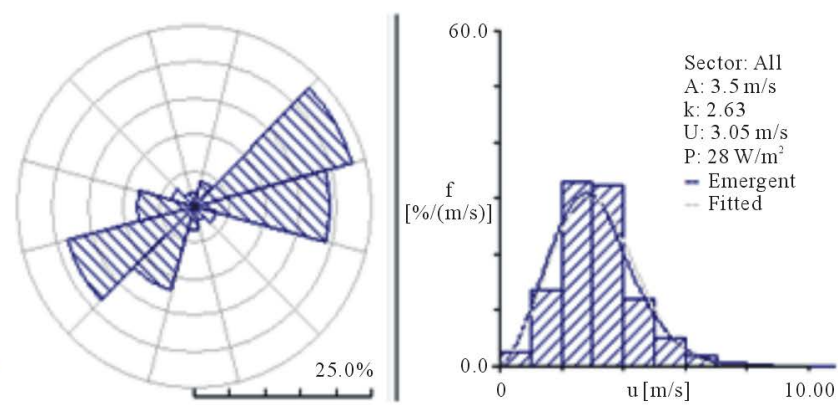

(b)
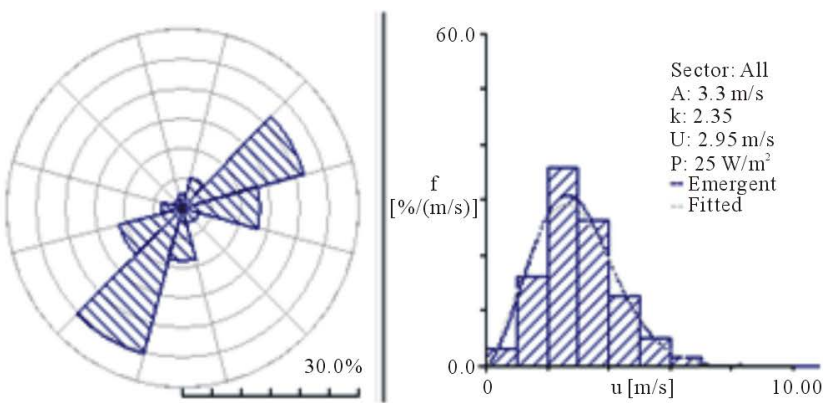

(d)
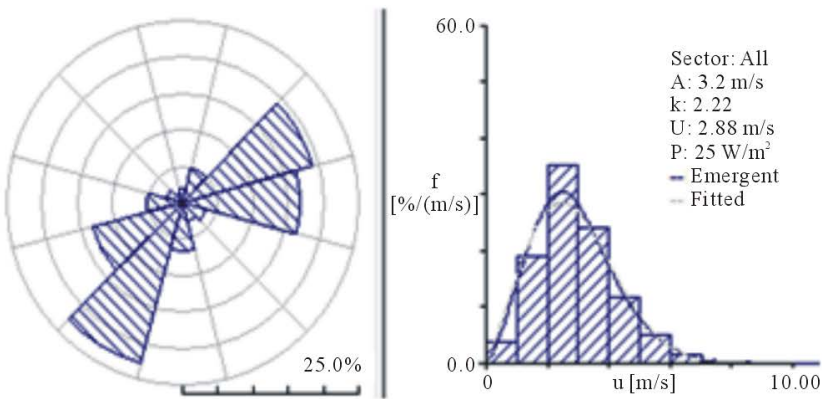

(f)
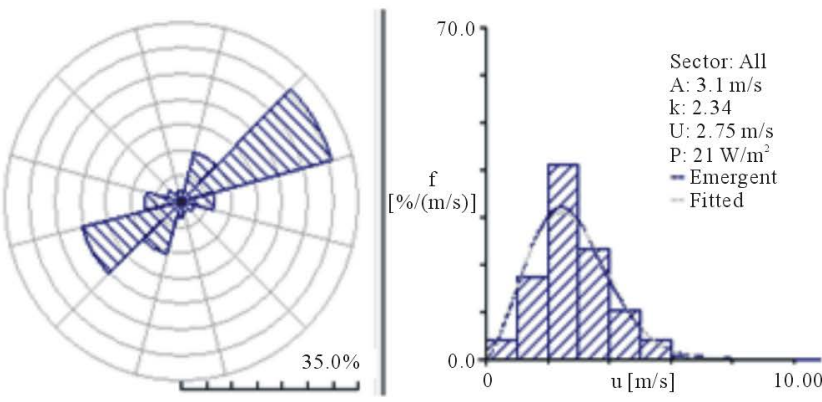

(h)
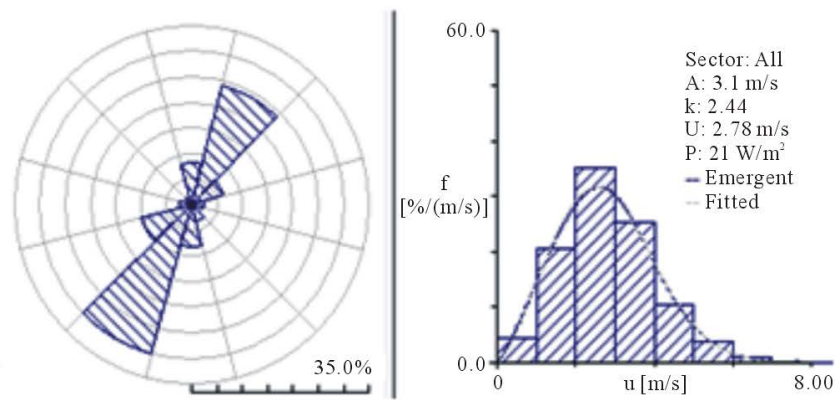

(j) 


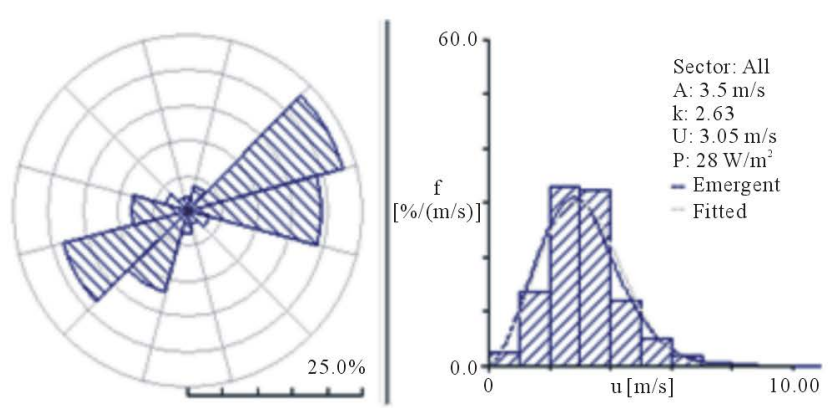

(k)
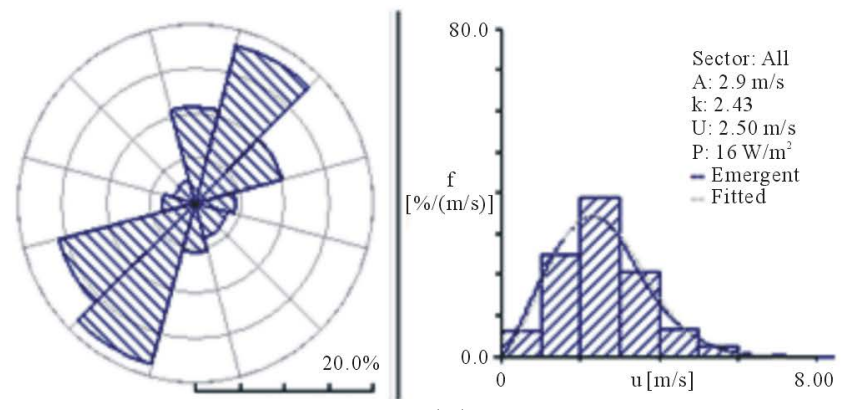

(m)
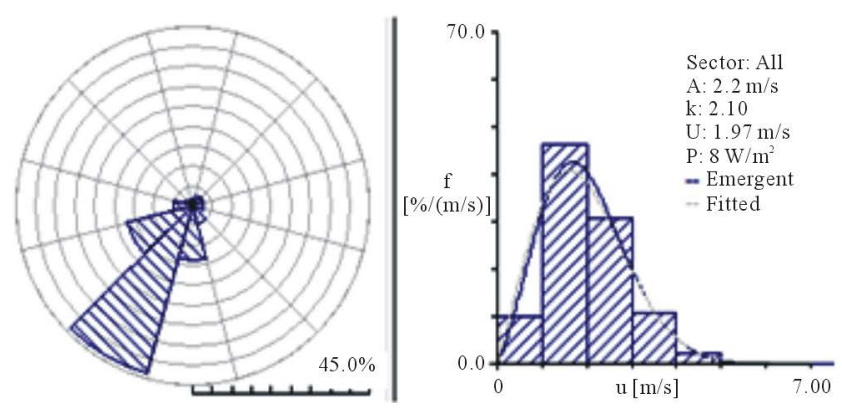

(o)
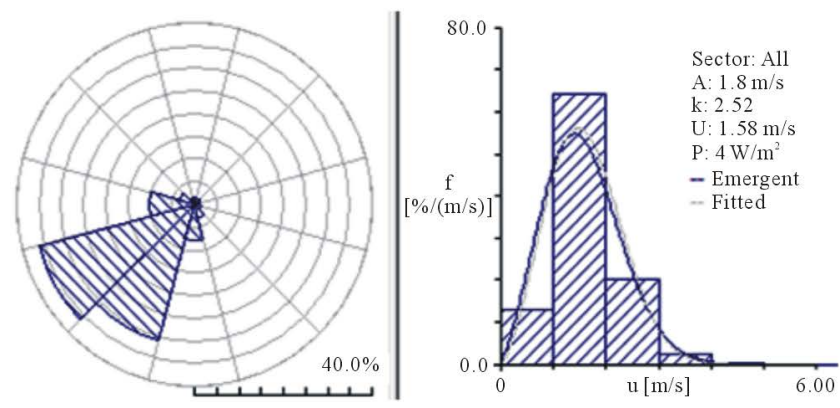

(q)
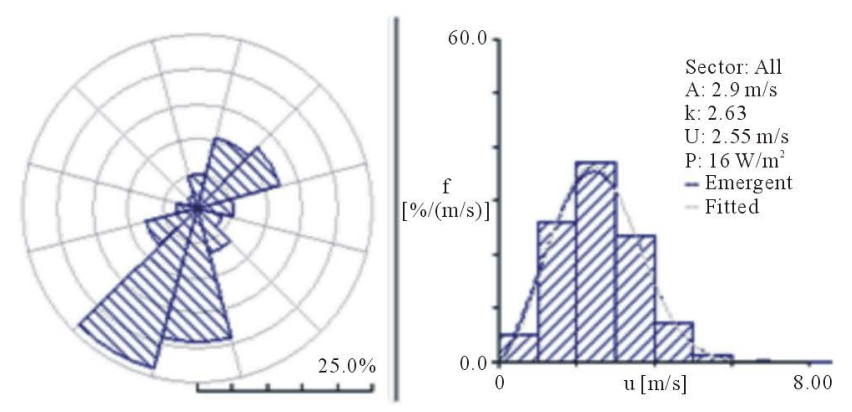

(1)
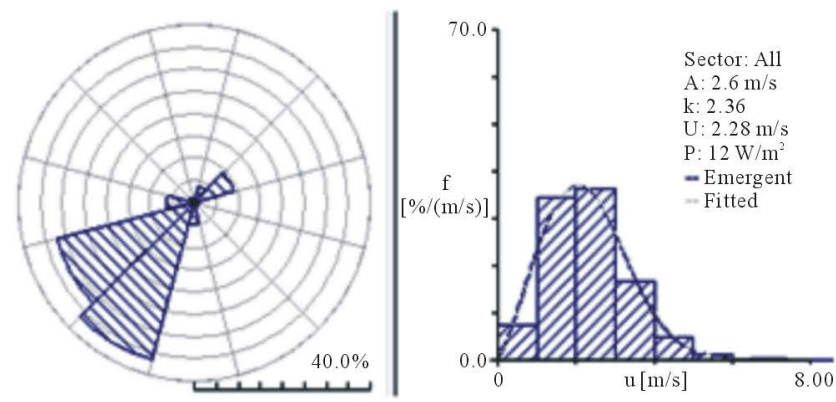

(n)
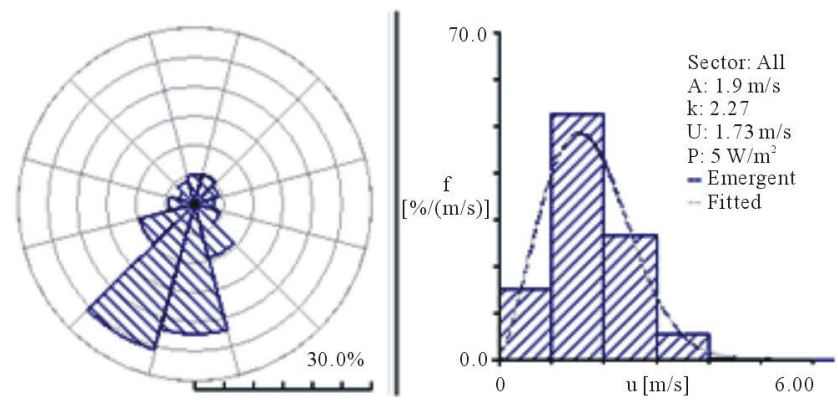

(p)
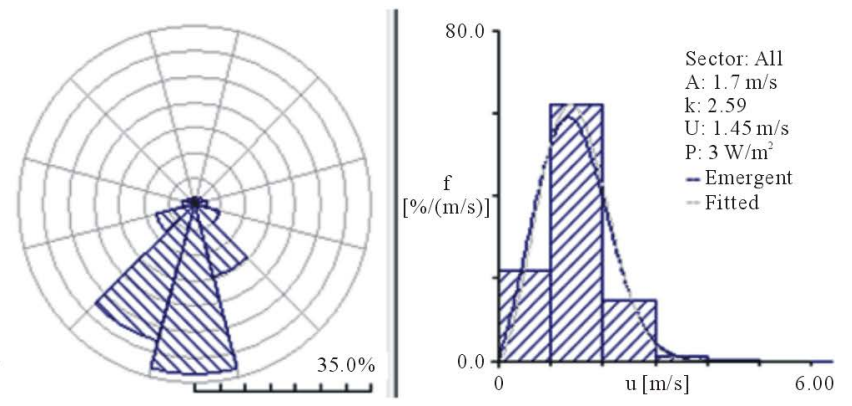

(r)

Figure 24. (a)-(d) Sectorwise wind directions at 10 m AGL for Nguru, Katsina, Maiduguri and Sokoto, respectively; (e)-(h) Sectorwise wind directions at $10 \mathrm{~m}$ AGL for Zaria, Gusua, Potiskum and Kano, respectively; (i)-(l) Sectorwise wind directions at $10 \mathrm{~m}$ AGL for Kebbi, Gombe, Kaduna and Yelwa, respectively; (m)-(p) Sectorwise wind directions at 10 m AGL for Bauchi, Makurdi, Lokoja and Bida, respectively; (q), (r) Sectorwise wind directions at $10 \mathrm{~m}$ AGL for Benin and Calabar, respectively.

surrounding tall buildings and skyscrapers, causing wind flow obstruction and deflection. Furthermore, the South-West of Nigeria is a very poor region for wind energy investment and should not be considered for grid-tie application except if offshore wind farms would be developed close to Gulf of Guinea and integrated into the transmission network in Lagos.

The comparisons of the mean wind speeds of 18 synoptic stations derived from the bilinear interpolation of the remapped and actual wind fields are presented in Figure 20. In addition, the wind and percentage errors in 
temporal resolution of 00:00:00, 06:00:00, 12:00:00 and 18:00:00 UTC for a 10 years period have been estimated from the remapped and actual wind speed values (see Table 4). The annual mean wind errors and percentage errors for each synoptic station differ from one wind location to another. The estimated wind speed discrepancies show that the wind speed dataset on a field of grid resolution of $0.25^{\circ} \times 0.25^{\circ}$ is suitable and could be substituted with a gridded dataset on $0.125^{\circ} \times 0.125^{\circ}$ grid resolution for smooth and flat terrain. However, the wind speed biases increase at mountains and hill tops with complex topography because of limitation of the distance-weighted averag technique in capturing this terrain complexity during remapping.

The low quality of surface wind observations available for this study makes detailed accuracy comparisons difficult with ERA-Interim reanalysis wind for the synoptic stations. High-quality wind observations at synoptic stations in Nigeria are often not available in long-term period as deployment is often made for routine weather forecasts and not for energy application. However, the hourly surface wind available for 18 synoptic stations were obtained and compared with the interpolated synoptic stations as presented in Figures 21-23. The wind speed discrepancies could not be estimated because of the missing surface wind observations at the different time of the year. It is expected that the surface wind observations at the considered synoptic stations would be higher than the ERA-Interim reanalysis wind dataset obtained from the atmospheric model simulation.

\section{Conclusion \& Recommendation}

The remapping of ERA wind field at $0.25^{\circ} \times 0.25^{\circ}$ grid resolution based on a distance-weighted averaging for studying the wind flow in Nigeria has been presented. The estimated wind speed biases show that a gridded wind speed dataset at $0.25^{\circ} \times 0.25^{\circ}$ resolution is suitable and can be substituted with a gridded dataset at $0.125^{\circ}$ $\times 0.125^{\circ}$ grid resolution. The wind potential sites for grid-tie electrification in northern region such as Sokoto, Katsina, Nguru, Gusua, Birnin Kebbi, Maiduguri, Zaria, Potiskum, Cashua, Hadejia and Kaduna have been identified and should be explored for medium-scale energy conversion at a higher altitude AGL. The geographical locations such as Lagos, Ogun, Oyo, Osun, Ekiti and Ondo states are poor wind regime and unsuitable for enery application based on the wind flow study conducted for 10 years period. A high-quality surface wind speed observations at these synoptic stations in Nigeria for long-term period can be acquired if available for ascertaining the listed wind sites in North and South-West regions of Nigeria. The integration of other forms of renewable energy can be possible if overhauling of existing transmission lines is done and new networks are built to accommodate different energy sources (i.e. energy mix). The procedures for transformation of gridded wind datasets from one resolution to another could be tested and compared with different atmospheric model simulations. Finally, cost analysis model should be developed before wind energy investment in Nigeria.

\section{Acknowledgements}

The financial support received from the Ekiti State Government (NG) for this project is acknowledged. The data exchange from the National Ocean and Atmospheric Administration (NOAA) is acknowledged.

\section{References}

[1] Nilsson, K. and Ivanell, S. (2010) Wind Energy. Gotland University, Visby.

[2] Aidan, J. and Ododo, J.C. (2010) Wind Speed Distributions and Power Densities of Some Cities in Northern Nigeria. Journal of Engineering and Applied Sciences, 5, 420-426. http://dx.doi.org/10.3923/jeasci.2010.420.426

[3] Ohunakin, O.S. (2011) Wind Characteristics and Wind Energy Potential Assessment in Uyo, Nigeria. Journal of Engineering and Applied Sciences, 6, 141-146. http://dx.doi.org/10.3923/jeasci.2011.141.146

[4] Ojosu, J.O. and Salawu R.I. (1990) Wind Energy Development in Nigeria. Nigerian Journal of Solar Energy, 9, $29-32$.

[5] Ojosu, J.O. and Salawu R.I. (1990) Survey of Wind Energy Potential in Nigeria. Solar \& Wind Technology, 7, 155167. http://dx.doi.org/10.1016/0741-983X(90)90083-E

[6] Adekoya, L.O. and Adewale, A.A. (1992) Wind Energy Potential of Nigeria. Renewable Energy, 2, 35-39. http://dx.doi.org/10.1016/0960-1481(92)90057-A

[7] Anyanwu, E.E. and Iwuagwu, C.J. (1995) Wind Characteristics and Energy Potentials for Owerri, Nigeria. Renewable Energy, 6, 125-128. http://dx.doi.org/10.1016/0960-1481(94)00028-5

[8] Agbaka, A.C. (1987) Experimental Investigation of the Possible Correction of Wind Speed on Insolation. Energy Conversion \& Management, 27, 45-48. http://dx.doi.org/10.1016/0196-8904(87)90051-3 
[9] Igbokwe, M.U. and Omekara C.O. (2002) Stochastic Simulation of Hourly Average Wind Speed in Umudike, South-East Nigeria. Global Journal of Mathematical Sciences, 1, 59-66. http://dx.doi.org/10.4314/gjmas.v1i1.21323

[10] Medugu, D.W. and Malgwi, D.I. (2005) A Study of Wind Energy Potential: Remedy for Fluctuation of Electric Power in Mubi, Adamawa State, Nigeria. Nigerian Journal of Physics, 17, 40-45.

[11] Ngala, G.M., Alkali, B. and Aji, M.A. (2007) Viability of Wind Energy as a Power Generation Source in Maiduguri, Borno State, Nigeria. Renewable Energy, 32, 2242-2246. http://dx.doi.org/10.1016/j.renene.2006.12.016

[12] Oriaku, C.I., Osuwa, J.C., Asiegbu, A.D., Chukwu, G.U. and Kanu, C.O. (2007) Frequency Distribution Analysis of Available Wind Resources in Umudike, Abia State, Nigeria, for Wind Energy Conversion System Design. Pacific Journal of Science \& Technology, 8, 203-206.

[13] Garba, A.D. and Al-Amin, M. (2014) Assessment of Wind Energy Alternative in Nigeria from the Lessons of the Katsina Wind Farm. Civil and Environmental Research, 6, 91-94.

[14] Pedersen, B.M., Hansen, K.S., Øye, S., Brinch, M. and Fabian, O. (1992) Some Experimental Investigations on the Influence of the Mounting Arrangements on the Accuracy of Cup-Anemometer Measurements. Journal of Wind Engineering and Industrial Aerodynamics, 39, 373-383. http://dx.doi.org/10.1016/0167-6105(92)90561-N

[15] (2010) Best Practice Guidelines for Mesoscale Wind Mapping Projects for the World Bank. 1-40.

[16] Petersen, E.L., Mortensen, N.G., Landberg, L., Højstrup, J. and Frank, H.P. (1998) Wind Power Meteorology. Part II: Siting and Models. Wind Energy, 1, 55-72. http://dx.doi.org/10.1002/(SICI)1099-1824(199812)1:2<55::AID-WE5>3.0.CO;2-R

[17] Dee, D.P., Uppalaa, S.M., Simmonsa, A.J., Berrisford, P., Poli, P., Kobayashib, S., Andraec, U., Balmaseda, M.A., Balsamo, G., Bauer, P., Bechtold, P., Beljaars, A.C.M., van de Bergd, L., Bidlot, J., Bormann, N., Delsol, C., Dragani, R., Fuentes, M., Geer, A.J., Haimbergere, L., Healy, S.B., Hersbach, H., Hólm, E.V., Isaksen, L., Kållberg, P., Köhler, M., Matricardia, M., McNally, A.P., Monge-Sanz, B.M., Morcrettea, J.-J., Park, B.-K., Peubeya, C., de Rosnay, P., Tavolato, C., Thépaut, J.-N. and Vitarta, F. (2011) The ERA-Interim Reanalysis: Configuration and Performance of the Data Assimilation System. Quarterly Journal of the Royal Meteorological Society, 137, 553-597. http://dx.doi.org/10.1002/qj.828

[18] Lavagnini, A., Sempreviva, A.M., Transerici, C., Accadia, C., Casaioli, M., Mariani, S. and Speranza, A. (2006) Offshore Wind Climatology over the Mediterranean Basin. Wind Energy, 9, 251-266. http://dx.doi.org/10.1002/we.169

[19] Jimenez, B., Durante, F., Lange, B., Kreutzer, T. and Tambke, J. (2007) Offshore Wind Resource Assessment with WAsP and MM5: Comparative Study for the German Bight. Wind Energy, 10, 121-134. http://dx.doi.org/10.1002/we.212

[20] Buzzi, A., Fantini, M., Malguzzi, P. and Nerozzi, F. (1994) Validation of a Limited Area Model in Cases of Mediterranean Cyclogenesis: Surface Fields and Precipitation Scores. Meteorology and Atmospheric Physics, 53, 53-67. http://dx.doi.org/10.1007/BF01029609

[21] http://apps.ecmwf.int/datasets/data/interim_full_daily/

[22] http://www.ncdc.noaa.gov/

[23] Lucchesi, R. (2008) File Specification for MERRA Products. Global Modeling and Assimilation Office Report, Version 2.1, 8.

[24] Fadare, D.A. (2008) A Statistical Analysis of Wind Energy Potential in Ibadan, Nigeria, Based on Weibull Distribution Function. Pacific Journal of Science and Technology, 9, 110-119. 